\title{
Article \\ Multiphysics Modeling and Material Selection Methods to Develop Optimal Piezoelectric Plate Actuators for Active Noise Cancellation
}

\author{
Dessalew Molla $^{1}$, Marek Płaczek ${ }^{2, *}$ a and Andrzej Wróbel ${ }^{2}$ \\ 1 Department of Mechanical Engineering, Wolayta Sodo University, Wolayta Sodo 138, Ethiopia; \\ dessmo1080@student.polsl.pl \\ 2 Department of Automation of Technological Process and Integrated Manufacturing System, \\ Silesian University of Technology, 44-100 Gliwice, Poland; andrzej.wrobel@polsl.pl \\ * Correspondence: marek.placzek@polsl.pl
}

check for

updates

Citation: Molla, D.; Płaczek, M.; Wróbel, A. Multiphysics Modeling and Material Selection Methods to Develop Optimal Piezoelectric Plate Actuators for Active Noise Cancellation. Appl. Sci. 2021, 11, 11746. https://doi.org/10.3390/ app112411746

Academic Editor: César M A. Vasques

Received: 18 October 2021

Accepted: 6 December 2021

Published: 10 December 2021

Publisher's Note: MDPI stays neutral with regard to jurisdictional claims in published maps and institutional affiliations.

Copyright: (c) 2021 by the authors. Licensee MDPI, Basel, Switzerland. This article is an open access article distributed under the terms and conditions of the Creative Commons Attribution (CC BY) license (https:// creativecommons.org/licenses/by/ $4.0 /)$.

\begin{abstract}
The performance of a piezoelectric actuator for active noise cancellation depends primarily on the quality of the actuator material and its design approach, i.e., single-layer or multi-layer actuators, stacks, benders, or amplified actuators. In this paper, material selection and multiphysics modeling were performed to develop an optimal piezoelectric plate actuator for active noise cancellation. The material selection process was analyzed using two multi-criteria decision making (MCDM) approaches for material selection, i.e., figure of merit (FOM) for actuators and the technique for order of performance by similarity to ideal solution (TOPSIS). Of the 12 state-of-the-art piezoelectric actuator materials considered in this article, PMN-28\% PT is the best material according to TOPSIS analysis, while $\left[\mathrm{Pb}\left(\mathrm{In}_{\frac{1}{2}} \mathrm{Nb}_{\frac{1}{2}}\right) \mathrm{O}_{3}\right] 24 \%-\mathrm{Pb}\left(\mathrm{Mg}_{\frac{1}{3}} \mathrm{Nb}_{\frac{1}{3}}\right) \mathrm{O}_{3}-\mathrm{PbTiO}_{3}$ (PIN24\%-PMN-PT) is the best material according to FOM analysis. The ranking of state-of-the-art piezoelectric material categories for actuators according to the two analysis is consistent and the category of monocrystalline piezoelectric materials has the highest actuation performance. The multiphysics modeling was performed using ANSYS Mechanical using two different approaches: one using Ansys Parametric Design Language (APDL) command fragments, the other installing the PiezoAndMEMS ACT extension in ANSYS. Static structure, modal, and harmonic response analyses were performed to determine an optimal pair of piezoelectric plates to be used as an actuator for active noise cancellation. A pair of plates of the same materials, but of different dimensions turns out to be the optimal piezoelectric plate actuator for active noise reduction, according to the two multiphysics modeling methods.
\end{abstract}

Keywords: piezoelectric plate actuator; multi-criteria decision making; figure of merit; TOPSIS algorithm; multiphysics modeling; ANSYS MAPDL; piezo and MEMS extension; polarization

\section{Introduction}

The negative effects of vibration in machine tools, civil infrastructures, automotive, and aerospace are huge and enormous. For instance, in the machine tool industry, mechanical vibration reduces both production rate and end-product quality, and shortens the service life of machine components, as assessed by [1,2]. Various traditional methods, such as passive insulators and dampers, have been used to dampen mechanical vibrations in various fields of engineering [3]. However, due to advances in digital signal processing (DSP), sensors, and actuators technologies, and the limitations in the effectiveness of traditional vibration damping mechanisms [4], a great emphasis has been placed on active vibration control over the past two decades. Today, active vibration control is a vast research area that synergistically integrates interdisciplinary technologies such as mechanical and electrical components. The fundamental components of active vibration control are the actuator, sensor, controller, and mechanical structure influenced by the disturbance. The main function of the actuators in active vibration control is to counteract the impact of 
the disturbance on the structure (mechanical body) by utilizing control signals generated intelligently by the controllers using input signals from sensors that sense the nature and magnitude of the disturbance. This way, the control system can reduce and/or cancel the disturbance by the principle of destructive interference. While there are different types of actuators such as electric, hydraulic, pneumatic, and piezo, to name a few, the only type of actuator focused on in this thesis is the piezoelectric actuator.

Before implementing and manufacturing any active vibration control systems, it is important to ensure the feasibility and reliability of the control system in the specific area. According to [5], one of the determinants of the feasibility and reliability of active vibration control is the dynamics of the actuator (piezoelectric actuator in this article) that dampen the unwanted vibration on the mechanical body with the help of commands from the controller. In turn, the performance of any piezoelectric actuator depends primarily on the quality of the actuator material [2] and its design approach [6], i.e., single-layer or multi-layer actuators, stacks, benders, or amplified actuators.

Not only for piezoelectric actuators, but also in any engineering design, material selection is a fundamental and crucial step, since proper material selection provides better quality, reliability, extended product life, and economic feasibility. Material selection in most engineering design processes, including piezoelectric actuators, is a multi-criteria decision making (MCDM) problem, as there are many constraints and several conflicting requirements to be met [7]. In addition to this, the availability of a number of potential materials for a specific area of application, such as piezoelectric actuators, makes the material selection a daunting task and requires a precise and efficient selection method. In this regard, different techniques and algorithms have been applied in the material selection problem and they are generally categorized into multi-objective decision making (MODM) and multi-attribute decision making (MADM) [7]. In this work, two approaches were applied in order to select the optimum material for the piezoelectric actuator. The first method was based on the figures of merit (FOM) approach under MODM, and the second was the technique for order of preference by similarity to the ideal solutions (TOPSIS), which is the most common material selection algorithm under MADM [7].

Different approaches to piezoelectric actuator design have been used to develop highperformance actuators with relatively large displacement and high blocking force. Monolayer, multi-layer, stack, bending, or amplified actuators are the common approaches [8].

In recent years, researchers have been studying piezoelectric plate actuators for use in active vibration cancelation, for example, in the articles [9-11]. However, most piezoelectric actuators are generally limited to either discrete rectangular patches or a single thin sheet of material in order to provide adequate actuated performance. In the discrete patch system, one of the major drawbacks is the management of higher modes, which results in highly involved control schemes that are difficult to implement, as mentioned by [12]. The same source also stated that a single sheet form exhibits modal phase cancellation, which severely restricts the ability to control the structure's higher vibration modes.

The voltage-strain sensitivity of a single piezoelectric patch, whether one-sided or bimorph, is rather low, so it is unable to generate considerable control force [13]. Increasing the actuator sensitivity can be achieved by using very high input voltages, but this can lead to problems such as patch burning and extra safety requirements for working with high voltages, as confirmed by the same source. In addition, the high voltages are not usually supplied by the work environment.

Considered the abovementioned limitations, multi-layer piezoelectric actuators (MPA) were suggested by $[12,13]$ as enhanced vibration control actuators. According to these two sources, the MPA is a simple method that uses a larger number of layers at the same point, one below the other in the thickness direction, and drives the same input voltage for every layer. The research by [12] performed active control experiments on a cantilever honeycomb sandwich panel (CHSP) using an MPA. These experiments included the resonant vibration control and the sinusoidal sweep of the control system for different piezoelectric layer numbers. The results showed that the MPA could effectively control 
the vibration of the high damping HSP, and the control performance per voltage by the proposed actuator could be improved significantly by increasing the piezoelectric patch number. Consequently, the MPA exhibited better actuation capability than that with only a single layer.

The work [13] investigated the voltage moment sensitivity of the MPA for vibration control, embedded into the surface of thin-walled beam-type structures. It was indicated that the MPA could increase the actuation performance for a low input voltage and, to a lesser extent, alter the mass, stiffness, and strength of the structure it controlled.

While the multilayer piezoelectric actuator (MPL) exhibits excellent actuation performance, unfortunately, researchers have not investigated the actuation performance of layers of different materials versus layers of the same materials, nor the cost-effectiveness of designing MPL actuators with only high-quality piezoelectric materials. These are the main motives of this article. Therefore, this article examines the relative performance of two pairs of piezoelectric plates. The candidate plate pairs are plates of the same dimensions/different materials and plates of the same material/different dimensions as shown in Figures $1 \mathrm{a}$ and $1 \mathrm{~b}$, respectively, so that both actuation performance and cost requirements are met.

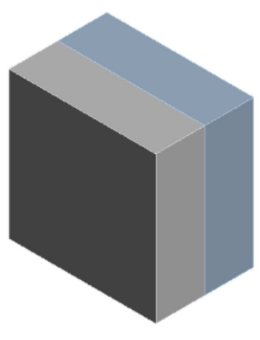

(a)

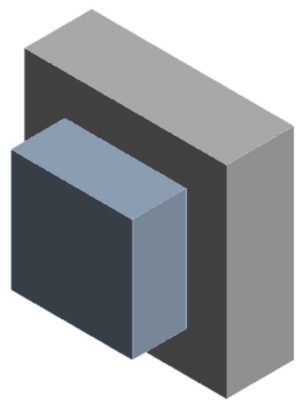

(b)

Figure 1. Potential piezoelectric actuators: (a) plates of the same dimensions/different materials and (b) plates of the same material/different dimensions.

Therefore, the primary objective of this article is to design and recommend a highperformance piezoelectric actuator for active vibration cancellation. In order to accomplish this main objective, this article addresses the selection of the optimal material for piezoelectric plate actuators and performs multiphysics modeling of individual piezoelectric plates and pairs of piezoelectric plates. This article uses two methods of multicriteria decision making (MCDM) to select materials, namely figure of merit (FOM) and technique for order preference by similarity to ideal solutions (TOPSIS). The goal of the multiphysics modeling in this article is to identify the superior pair of piezoelectric plates from the two candidates mentioned above.

The performance of active vibration control (AVC) systems has been improved by using one or a combination of the following methods: actuation system enhancement, detection system enhancement, and the use of a range of intelligent learning algorithms. Recursive least-squares algorithms (RLS), evolutionary genetic algorithms (GA), general regression neural network (GRNN), and adaptive neural fuzzy inference (ANFIS) are popular machine learning algorithms used to enhance AVC control mechanisms. However, the scope and area of interest for this work are limited to improving the actuation system of AVC.

\section{Materials and Methods}

\subsection{Research on State-of-the-Art Piezoelectric Materials}

This section of the article reviews state-of-the-art man-made piezoelectric materials in terms of their material properties, which are considered as figures of merits (FOM) 
in piezoelectric actuator applications. The key figure of merit in piezoelectric actuator application areas is the piezoelectric strain coefficient $d_{33}$ (longitudinal) or the piezoelectric stress coefficient $\varepsilon_{33}$ [14].

Piezoelectric materials are intelligent materials that generate an electrical signal when subjected to mechanical effect, and mechanical strain when subjected to electrical effect. The first phenomenon is called the direct piezoelectric effect, which is the principle of operation of piezoelectric sensors and generators, while the second is the reverse piezoelectric effect, which is the principle of operation of piezoelectric actuators and motors.

State-of-the-art synthetic piezoelectric materials can be categorized as single crystals, ceramics, polymers, composites, and piezoelectric thin films.

Single Crystal Piezoelectric Materials.

In the world of piezoelectric materials, well-known and high-performance single crystal piezoelectric materials are categorized under the lead-based relaxor-lead titanate $\left(\mathrm{Pb}(A B) \mathrm{O}_{3}-\right.$ $\left.\mathrm{PbTiO}_{3}\right)$ class, where $\left(A=\mathrm{Mg}^{2+}, \mathrm{Zn}^{2+}, \mathrm{Ni}^{2+}, \ldots, B=\mathrm{Nb}^{5+}, \mathrm{Ta}^{5+}, \mathrm{W}^{6+}, ..\right)$ [15]. The research carried out by [15-18] showed that the high performance of the aforementioned class of materials is due to the presence of a morphotropic phase boundary (MPB) in the crystal. Two important systems in the relaxor-PT family are $\mathrm{Pb}\left(\mathrm{Mn}_{1 / 2} \mathrm{Nb}_{2 / 3}\right) \mathrm{O}_{3}-\mathrm{PbTiO}_{3}$ (PMN-PT) and $\mathrm{Pb}\left(\mathrm{In}_{1 / 2} \mathrm{Nb}_{1 / 2}\right) \mathrm{O}_{3}-\mathrm{Pb}\left(\mathrm{Mn}_{1 / 2} \mathrm{Nb}_{2 / 3}\right) \mathrm{O}_{3}-\mathrm{PbTiO}_{3}$ (PIN-PMN-PT) [6].

Piezoelectric Ceramics.

Lead-based ceramics have been found to exhibit excellent piezoelectric properties and are used in a variety of electronic devices. Particularly, lead zirconate titanate $\left(\mathrm{Pb}\left[\mathrm{Zr}_{x} \mathrm{Ti}_{1-x}\right] \mathrm{O}_{3}\right.$, $0<\mathrm{x}<1$ ), more commonly known as PZT, and related compositions have been used in various sensors and actuators due to their excellent piezoelectric properties [6]. Extensive research has been carried out to optimize the piezoelectric properties of PZT using a variety of techniques. Of these techniques, the addition of various dopants or substitutional impurities has successfully tailored PZT ceramics to specific applications. Dopants can be donors or acceptors, depending on the characteristics of PZT to be optimized. The addition of donor dopants such as $\mathrm{La}^{+3}, \mathrm{~W}^{+6}, \mathrm{Nb}^{+5}$, and $\mathrm{Sb}^{+5}$ increases piezoelectric coefficient, dielectric constant, and electromechanical coupling factor [6]. Such ceramics obtained by adding donor dopant are called soft PZT ceramics and are therefore appropriate for low frequency actuators [6]. Among soft PZT ceramics, PZT-5A, PZT-5J, and PZT-5H are the most widely used ceramics for actuator applications, and the respective piezoelectric strain coefficients $d_{33}$ are 390,485, and $650 p C N^{-1}$ [19]. The addition of acceptor dopants such as $\mathrm{K}^{+}, \mathrm{Na}^{+}, \mathrm{Fe}^{+3}, \mathrm{Al}^{+3}$, and $\mathrm{Mn}^{+3}$ decreases the piezoelectric coefficient, dielectric constant, and electromechanical coupling factor. PZT-4 and PZT-8 are commonly used hard PZT materials in sensors, and their piezoelectric strain coefficients are 372 and 375 $p C N^{-1}$, respectively, as stated by $[6,19]$.

Lead-free piezoelectric ceramics.

Due to the fact that lead is toxic to the environment and causes serious environmental pollution, the development of lead-free piezoelectric ceramics has attracted great interest. Useful lead-free materials are often binary or ternary solid solutions of the following end-member compositions: barium titanate $\left(\mathrm{BaTiO}_{3} ; \mathrm{BT}\right)$, sodium bismuth titanate $\left(\left(\mathrm{Na}_{1 / 2} \mathrm{Bi}_{1 / 2}\right) \mathrm{TiO}_{3} ; \mathrm{NBT}\right)$, potassium bismuth titanate $\left(\left(\mathrm{K}_{1 / 2} \mathrm{Bi}_{1 / 2}\right) \mathrm{TiO}_{3} ; \mathrm{KBT}\right)$, potassium sodium niobate $\left(\mathrm{K}_{0.5} \mathrm{Na}_{0.5} \mathrm{NbO}_{3} ; \mathrm{KNN}\right)$, and bismuth ferrite $\left(\mathrm{BiFeO}_{3} ; \mathrm{BFO}\right)$, as mentioned by [20].

Commonly used state-of-the art binary lead-free piezoelectric materials are NBT-KBT, NBT-KNN, NBT-BT, NBT-BFO, KBT-BT, and KNN-BT, as illustrated by the same source [20].

Due to the limitations of the binary systems described above in terms of piezoelectric properties, they cannot replace PZT in all its applications. Therefore, much research has focused on new lead-free compositions that have become even more complex with the use of ternary solid solutions [20].

Piezoelectric polymers.

Piezoelectric polymer materials are also referred to as organic lead-free piezoelectric materials. According to the studies [21-24], piezoelectric polymers are commonly grouped 
based on their topology and dipole moment as described in Figure 2: bulk polymers, polymer composites, and voided charged polymers. Bulk polymers are solid polymer films that have the piezoelectric mechanism through their molecular structure and its arrangement. Composite polymers are polymer structures with integrated piezoelectric ceramics from which the piezoelectric effect is generated, according to $[25,26]$. These composites make use of the mechanical flexibility of polymers and the high electromechanical coupling of the piezoelectric ceramics [27-29]. For voided charged polymers, the piezoelectric properties are determined by internal dipoles when the gas voids are charged with an electric field. The gas voids are present in its thin polymer layer.

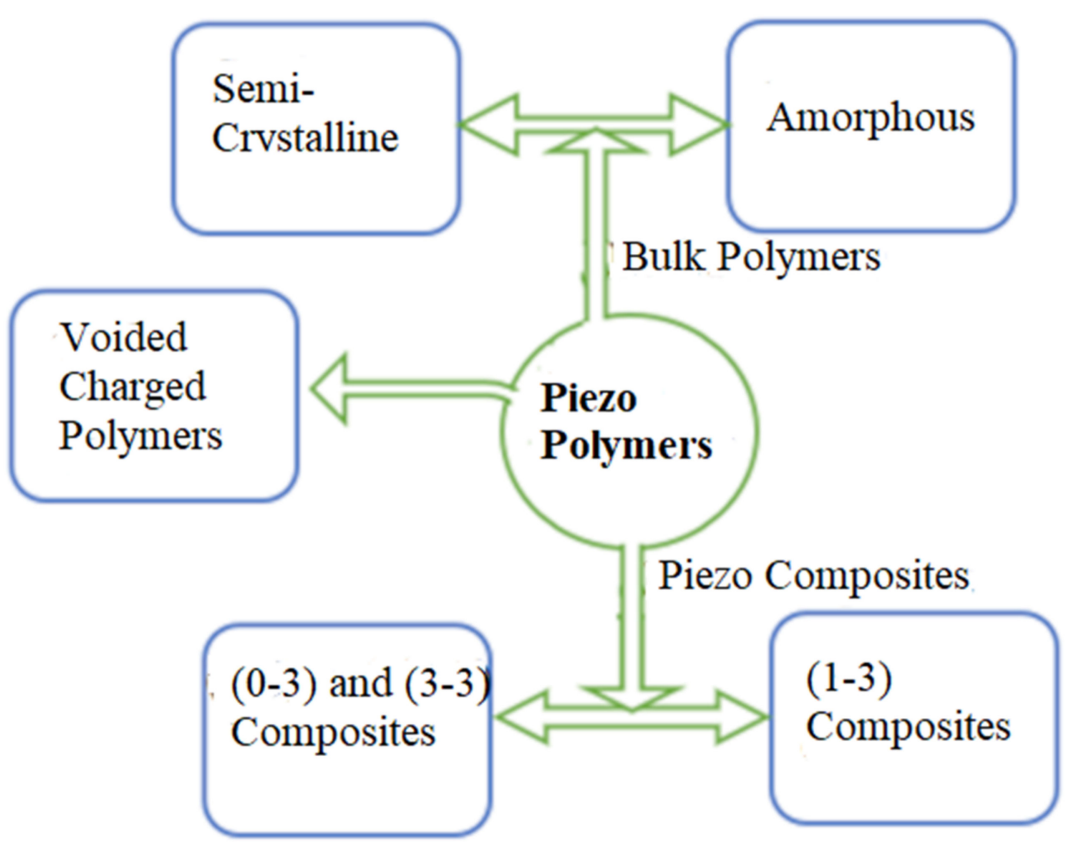

Figure 2. Schematic diagrams of piezoelectric polymer types.

Piezoelectric Thin Film.

In the current trend of Industry 4.0, which is characterized by miniaturization and integration, piezoelectric thin-film technology plays an indispensable role. In the development of nanoscale and microscale devices, piezoelectric thin-film technology plays a major role due to the additional functionality provided by electromechanical coupling and their micro-machining capability [30]. This has been proven by the increasing inclusion of piezoelectric thin films as functional materials for microelectromechanical (MEMS) and nanoelectromechanical (NEMS) systems.

The study [30] found that the advancement of thin-film piezoelectric materials is strongly related to the development and growth of bulk piezoelectric materials. Almost all of the state-of-the-art bulk piezoelectric materials discussed above can be used as thin-film piezoelectric materials with the help of different production technology, as stated by [31,32]. The same studies also mentioned that the two basic crystal structures of the thin films are wurtzite and perovskite structures. Under the category of wurtzite crystal structure, non-ferroelectric piezoelectric materials such as $\mathrm{ZnO}$ and $\mathrm{AlN}$ are the common materials and are suitable for high-frequency resonator applications, as asserted by the study.

\subsection{Material Selection}

When selecting a material for an engineering application, many constraints have to be followed and several requirements or objectives must be met. In most cases, the objectives and criteria in the material selection process are in conflicts and involve trade-offs among the criteria. In addition, there are many possible alternative materials for a specific 
engineering application. Because of these abovementioned facts, material selection process has been considered and treated as a multi-criteria decision-making (MCDM) problem [7].

Different MCDM methods have been successfully applied to select optimal piezoelectric materials for energy harvesters, actuators and sensors, materials for microelectromechanical systems (MEMS), and materials for hard coating [7].

Currently, many techniques and algorithms that are considered multi-criteria decision making (MCDM) methods have been developed and applied in the material selection process in order to facilitate the selection procedure and select the optimal material for a particular engineering application. These techniques and algorithms for material selection problems can be broadly divided into two types, namely multi-objective decision-making (MODM) methods and multi-attribute decision-making (MADM) methods [14].

\subsubsection{Multi-Objective Decision-Making (MODM)}

Multi-objective decision-making (MODM) optimizes various conflicting objectives that are part of a design problem by creating figures of merit (FOM) or performance indices for the relative evaluation and ranking of possible material candidates for a specific application [14]. The figure of merit (FOM) or performance index for a specific engineering application is a parameter of continuous value that is generated by using a known or supervised functional relationship between the various desired attributes of the material. For instance, the FOM for piezoelectric sensors is given by Equation (1) as:

$$
\frac{K^{2}{ }_{33}}{d_{33}\left(1-K^{2}{ }_{33}\right)},
$$

where: $K_{33}$ is the coupling coefficient and $d_{33}$ is the piezoelectric strain coefficient.

The FOM for piezoelectric actuators is given by the piezoelectric strain coefficient $e_{33}$ or piezoelectric strain coefficient $d_{33}$, to evaluate the performance of materials in the longitudinal mode [3].

In the case of piezoelectric energy harvesters, there are two FOMs given by Equations (2) and (3) to assess the material's performance in the longitudinal mode in resonance and off-resonance conditions respectively:

$$
\begin{gathered}
\frac{K^{2}{ }_{33} \times Q_{m}}{S_{11}}, \\
\frac{d_{33} \times g_{33}}{\tan \delta},
\end{gathered}
$$

where: $K_{33}$ is the coupling coefficient, $d_{33}$ is the piezoelectric strain coefficient, $S_{33}$ is the elastic compliance, $Q_{m}$ represents the mechanical quality factor, and $\tan \delta$ represents dielectric losses.

Therefore, in this method, the candidate material having the maximum FOM is considered as the optimum material for the given application. This method of material selection is considered as one of the most effective and efficient methods of material selection and is usually involved in design-related engineering activities [14].

\subsubsection{Multi-Attribute Decision-Making (MADM)}

Alternatively, MADM methods are used to make preferential decisions over available alternatives or candidates and rank them according to a standard and predefined algorithm, regardless of the functional relationship between the attributes of each alternative or candidate [7]. This method generally involves two main steps: first, desired traits of attributes are selected from among those selected for study, and then the candidate materials are compared and ranked according to their degree of similarity to the desired traits. The candidate material with the closest similarity or distance to the selected desired traits is considered to be the optimal material for the given application [7]. 
Under the MADM methodology, there are different philosophies that work with different approaches [33]. However, the popular method known as the technique for order preference by similarity to ideal solutions (TOPSIS), working with the reference level approach, is widely used for the material selection problem [14]. TOPSIS works based on the approach that positive and negative ideal solutions are created from a given set of data as reference levels and the optimum material is the one that lies closest to the positive ideal solution and furthest from the negative ideal solution, as illustrated in the Figure 3. The positive ideal solution is one that contains the best possible attributes from the given set of candidate materials; similarly, the negative ideal solution contains the worst possible attributes from the given set of candidate materials [14].

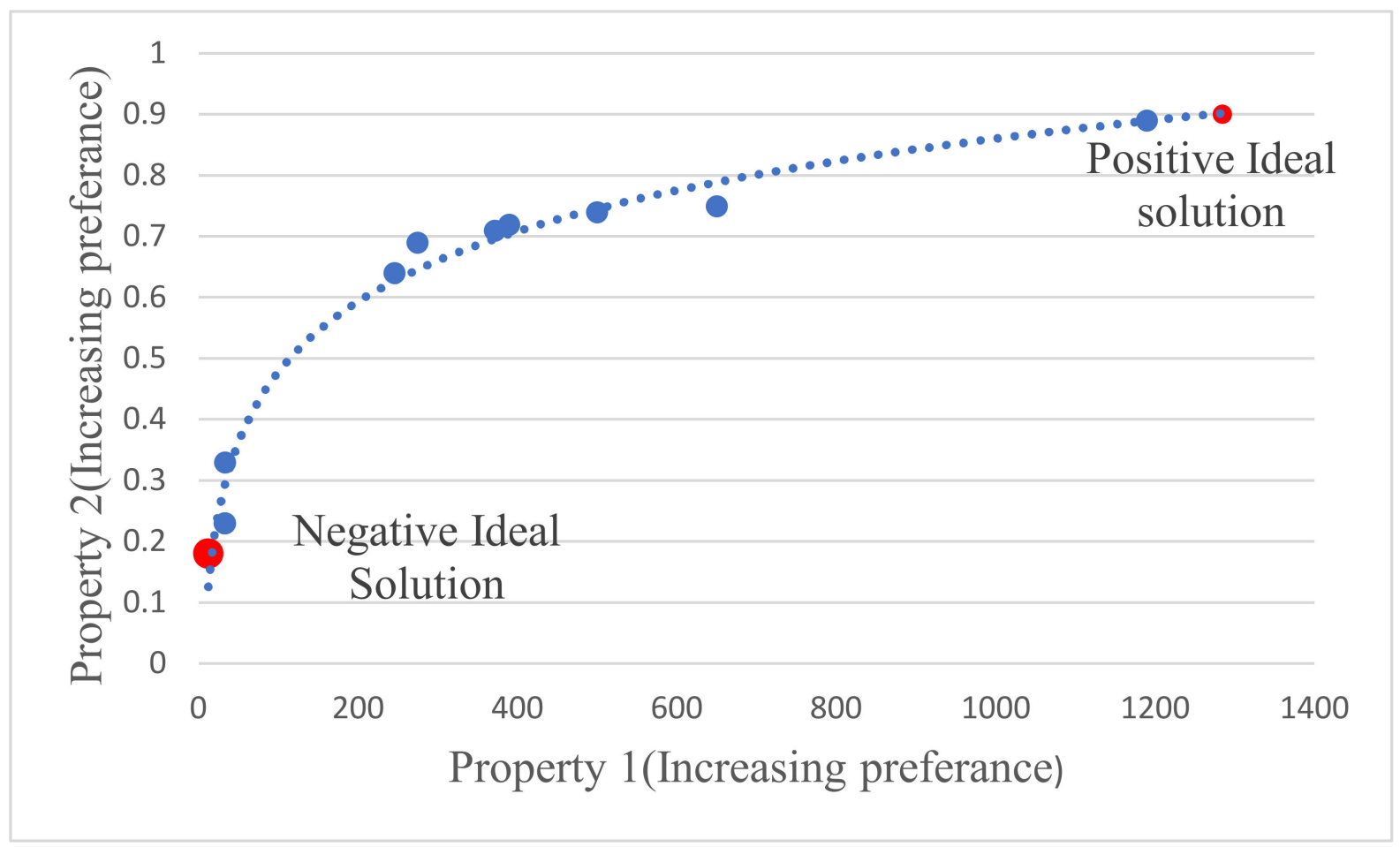

Figure 3. Graphical description of TOPSIS method.

The TOPSIS process is carried out as follows, according to the source [33]:

Step 1:

Create an evaluation matrix consisting of $\mathrm{m}$ alternatives and $\mathrm{n}$ criteria, with the intersection of each alternative and criteria given as $x_{i j}$; we therefore have a matrix $\left(x_{i j}\right)_{m \times n}$.

Step 2:

The matrix $\left(x_{i j}\right)_{m \times n}$ is then normalized to form the matrix $\left(R_{i j}\right)_{m \times n}=\left(r_{i j}\right)_{m \times n^{\prime}}$ using the linear normalization method:

$r_{i j}=\frac{x_{i j}}{\left(x_{i j}\right) \max }$, if the criterion is positive, $\mathrm{i}=1,2,3, \ldots, \mathrm{m}$ and $\mathrm{j}=1,2,3, \ldots . . \mathrm{n}$,

or:

$r_{i j}=\frac{\left(x_{i j}\right) \min }{x_{i j}}$,if the criterion is negative, $\mathrm{i}=1,2,3, \ldots, \mathrm{m}$ and $\mathrm{j}=1,2,3, \ldots . ., \mathrm{n}$.

Step 3:

Calculate the objective weighted normalized decision matrix using the equation:

$$
\left(T_{i j}\right)_{m \times n}=w \times\left(R_{i j}\right)_{m \times n^{\prime}}
$$


where $\mathrm{w}$ is the weight factors for criteria.

Step 4:

Determine the worst alternative $A_{w}$ and the best alternative $A_{b}$ :

$$
\begin{aligned}
& A_{w}=\left[\min \left(t_{i j} \mid i=1,2,3, \ldots, m\right) \text { for each } j=1,2,3, \ldots . ., n\right], \\
& A_{b}=\left[\max \left(t_{i j} \mid i=1,2,3, \ldots, m\right) \text { for each } j=1,2,3, \ldots . ., n\right] .
\end{aligned}
$$

Step 5:

Calculate the $L^{2}$ distance between the target alternative $i$ and the worst condition $A_{w}$ :

$$
d_{i w}=\sqrt{\left(\sum_{j=1}^{n}\left(t_{i j}-t_{w j}\right)^{2}\right)}, \quad i=1,2,3, \ldots, m,
$$

and the distance between the alternative $i$ and the best condition $A_{b}$ :

$$
d_{i b}=\sqrt{\left(\sum_{j=1}^{n}\left(t_{i j}-t_{b j}\right)^{2}\right)}, \quad i=1,2,3, \ldots, m .
$$

Step 6:

Calculate the similarity to the worst condition:

$$
s_{i w}=\frac{d_{i w}}{\left(d_{i b}+d_{i w}\right)}, 0 \leq s_{i w} \leq 1, \quad i=1,2,3, \ldots, m,
$$

where $s_{i w}=1$ if and only if the alternative solution has the best condition; and $s_{i w}=0$ if and only if the alternative solution has the worst condition.

Step 7:

Rank the alternatives according to $s_{i w}(i=1,2,3, \ldots, m)$.

\subsection{Multiphysics Modeling Using ANSYS Mechanical}

After selecting two optimal materials at the material selection stage, piezoelectric material properties required to fully define the selected materials were collected for modeling using ANSYS Multiphysics. The properties of piezoelectric material were available in the Institute of Electrical and Electronics Engineers (IEEE)'s standard matrix formats, which were not ANSYS compatible. Conversion of property matrices was required, so various matrix operations were performed to obtain the properties in the required ANSYS format. The order of rows and columns in ANSYS matrices tensor notation is $x, y, z, x y, y z, x z$ instead of $x, y, z, y z, x z, x y$, which is the order of rows and columns in standard IEEE forms based on $[34,35]$. Then, geometric models of two plates of different dimensions and of three different paired plates were generated using SOLIDWORKS. Finally, static response analyses were performed on two separate plates made of two selected piezoelectric materials and on three different pairs of the two plates to determine their longitudinal (3-3) free displacements by applying a 1000V DC voltage difference on each plate in all analyses. Of the three pairs of plates, two were the potential piezoelectric plate actuators listed in Figure 1, and the third pair, made of plates of the same materials and dimensions, served as a reference. After comparing the longitudinal (3-3 mode) free displacement results of the candidate actuators, the optimal actuator having higher longitudinal free displacement was selected and modal and harmonic response analyses were performed on it to determine its frequency characteristics.

In terms of piezoelectric finite element formulations and applications, early studies focused on 3D elements with nodal electric potential degrees of freedom. They take into account the surface characteristics and full electromechanical coupling inherent in piezoelectric models. According to the source, these were too thick to model very thin structures. Thus, in recent years, attention has been focused on 2D and 1D elements 
such as shells, plates, and beams, despite the difficulty in using conventional midplane formulations that take into account potentials on upper and lower surfaces. An overview of the development of FEM based on element types and degrees of freedom is presented in [36].

According to the above investigations, the FEM implementation in this work was based on the standard nodal approach extended for piezoelectric materials by using 3D elements. In order to account for electrical-mechanical coupling in piezoelectric materials, an additional degree of freedom for electrical potential was added to each node in those elements, together with their standard displacement unknowns. Specifically, hexahedral elements are considered in this work due to their superior accuracy and robustness compared to tetrahedral elements [37]. Tetrahedral elements are more effective in handling complex geometries [37] often encountered in practical applications, but due to the structural simplicity of our problem, they are not taken into account in this work. The thicknesses of the piezoelectric plates in this article are $8 \mathrm{~mm}$ and $10 \mathrm{~mm}$, which are sufficient for modeling using 3D finite elements.

In order to perform the abovementioned analyses, two different methods were followed for each analysis and the results from both methods were compared.

Method 1: Using Ansys Parametric Design Language (APDL) command snippets in ANSYS Mechanical.

Command snippets are small pieces of code in the ANSYS Mechanical APDL language that help to take advantage of the undisclosed capabilities of the ANSYS Mechanical interface. They are added to the project tree as commands for ANSYS Mechanical models. When the solver file is written, ANSYS Mechanical inserts the snippets into the command stream. In general, this approach is used to access ANSYS Mechanical solver capabilities that are not supported by the interface and to access and track these functions from within the ANSYS mechanical model.

In this method, with the help of APDL command snippets, mesh method, mesh element type, electrical boundary conditions, and electrical properties (piezoelectric stress and dielectric coefficient matrices) of the piezoelectric models were inserted.

The SOLID226 element type was used for the meshing in this method of analysis. It is one of the solid coupled-field elements that support piezoelectric analysis and it has twenty nodes with up to six degrees of freedom per node [38]. For the contact surfaces of paired plates, the contact element types CONTA174, and TARGE170 were assigned automatically. CONTA174 is a 3-D 8-node surface-to-surface contact element used to represent contact and sliding between 3-D target surfaces and a deformable surface defined by this element. TARGE170 is used to represent various 3-D "target" surfaces for the associated contact elements CONTA174 and other contact elements.

For the sake of simplicity, fixed support on the rear face of the plate on the XY plane was assumed as the mechanical boundary condition for all analysis types and cases.

The polarization of the plate was in the direction of $Z$-axis and the electrodes of the plates were modeled by the "named selection of rear and front faces of the plate" procedure. The DC voltages on the electrodes were applied using MAPDL command snippets as:

d, neg, volt, 0

$d$, pos, volt, 1000

where: "neg" and "pos" are the names of ground electrode on front face of the plate and positive electrode on rear face of the plate, respectively.

Method 2: Installing the PiezoAndMEMS extension in ANSYS Mechanical.

The ANSYS Customization Toolkit (ACT) helps to add external tools as extensions to customize the interface and increase the functional capabilities of ANSYS Mechanical. The ACT PiezoAndMEMS extension is a customization made with ACT to add piezoelectric and MEMS modeling capabilities to ANSYS Mechanical.

In this method of modeling, the mechanical properties (anisotropic elasticity) of the models were inserted into ANSYS Mechanical in tabular format, in same way as in Method 1. However, for the electrical properties, the plate was considered as a piezoelectric body 
polarized along the Z-axis with the help of the installed PiezoAndMEMS ACT extension, and the dielectric permittivity at constant strain and piezoelectric stress properties of the models were inputted in the detail section of the model.

\section{Results}

Potential candidate or alternative state-of-the-art piezoelectric materials for the material selection analysis were selected from each piezoelectric material category discussed in the material section on the basis of their performance for actuator applications, i.e., based on their $d_{33}$ values. The selected alternative state-of-the-art piezoelectric materials and their properties are presented in Tables 1 and 2.

Table 1. Potential piezoelectric materials for the material selection analysis and their material categories.

\begin{tabular}{cc}
\hline Material & Category \\
\hline PZT-5H & Soft ceramics \\
PZT-5J & Soft ceramics \\
PZT-5A & Soft ceramics \\
PZT-4 & Hard ceramics \\
PZT-8 & Hard ceramics \\
PVDF & Polymer \\
(PVDF-TrFE)75/25 & Polymer \\
PZT film $(4 \mu \mathrm{m}$ on Si) & Thin film \\
ZnO film & Thin film \\
AIN film & Thin film \\
PMN-28\% PT & Single crystal binary composite \\
PIN24\%-PMN-PT & Single crystal ternary composite \\
\hline
\end{tabular}

Table 2. Potential piezoelectric materials and their properties selected for the analysis.

\begin{tabular}{cccccc}
\hline Materials & $k_{33}$ & $S^{E_{33}}\left(p \frac{m^{2}}{N}\right)$ & $\varepsilon^{T}{ }_{33}\left(\frac{n F}{m}\right)$ & $d_{33}\left(p \frac{C}{N}\right)$ & Reference \\
\hline PZT-5H & 0.75 & 21.0 & 33.63 & $650[19]$ & {$[19]$} \\
PZT-5J & 0.74 & 18.8 & 18.59 & $500[19]$ & {$[19]$} \\
PZT-5A & 0.72 & 18.6 & 15.93 & $390[19]$ & {$[19]$} \\
PZT-4 & 0.71 & 17.0 & 14.60 & 372 & {$[38]$} \\
PZT-8 & 0.64 & 13.5 & 9.8 & 275 & {$[38]$} \\
PVDF & 0.18 & 472 & $6.73 \times 10^{-2}$ & 32.5 & {$[21,39]$} \\
(PVDF-TrFE)75/25 & 0.23 & 300 & $7.0 \times 10^{-2}$ & 33.5 & {$[21,39]$} \\
PZT film (4 $\mu$ m on Si) & 0.69 & 14.7 & 12.39 & 246 & {$[40]$} \\
ZnO film & 0.33 & 4.74 & $7.2 \times 10^{-2}$ & 12 & {$[30,40]$} \\
AIN film & 0.24 & 2.53 & $8.85 \times 10^{-2}$ & 7 & {$[30,41]$} \\
PMN-28\% PT & 0.9 & 36.15 & 48.68 & 1190 & {$[39]$} \\
PIN24\%-PMN-PT & 0.89 & 49.04 & 42.06 & 1285 & {$[39]$} \\
\hline
\end{tabular}

Various physical/electrical properties affect the performance of a piezoelectric actuator. However, the piezoelectric strain coefficient $d$ is the most important piezoelectric property in determining the effectiveness of piezoelectric materials in actuator applications [6]. A high value of $d$ implies a high strain for a given applied voltage. In particular, in this work, the piezoelectric strain coefficient in the longitudinal mode $d_{33}$ is treated as the figure of merit (FOM) for piezoelectric materials for actuator application.

In addition to the piezoelectric strain coefficient $d$, other properties considered in this article for the TOPSIS approach were: coupling coefficient $K$, elastic compliance $S^{E}$ at constant electric field, and dielectric constant $\varepsilon^{T}$ at constant stress. From these properties, the desirable properties of piezoelectric materials for actuator applications are high values of $K, \varepsilon, e$, and a low value of $S$ [14].

The TOPSIS indices of the alternative materials are determined by considering the relative weights of $d_{33}, k_{33}, S^{E}{ }_{33}$, and $T_{33}$. For piezoelectric actuators, the relative importance 
of the piezoelectric strain coefficient is higher than that of the coupling coefficient and, in turn, higher than that of the dielectric constant [7]. However, the relative importance of the dielectric constant and compliance are assumed to be equal [7]. Thus, based on these assertations, relative weights of $30 \%, 25 \%, 22.5 \%$, and $22.5 \%$ were assumed for $d_{33}, k_{33}$, $S^{E}{ }_{33}$, and $T_{33}$, respectively, in this work.

The ranking of the above state-ot-the art piezoelectric materials according to the FOM and TOPSIS approaches is given in Table 3.

Table 3. Ranking of the piezoelectric materials for actuators according to FOM and TOPSIS approaches.

\begin{tabular}{|c|c|c|c|c|c|c|c|}
\hline Material & $k_{33}$ & $\begin{array}{c}S^{E} \\
\left(p \frac{m^{2}}{N}\right)\end{array}$ & $\begin{array}{l}\varepsilon^{T} 33 \\
\left(\frac{n F}{m}\right)\end{array}$ & $\begin{array}{c}d_{33} \\
\left(p \frac{C}{N}\right)\end{array}$ & $\begin{array}{l}\text { FOM } \\
\text { Rank }\end{array}$ & $\begin{array}{c}\text { TOPSIS } \\
\text { Index }\end{array}$ & $\begin{array}{c}\text { TOPSIS } \\
\text { Rank }\end{array}$ \\
\hline PIN24\%-PMN-PT & 0.89 & 49.04 & 42.06 & 1285 & 1 & 0.6558 & 2 \\
\hline PMN-28\% PT & 0.90 & 36.15 & 48.68 & 1190 & 2 & 0.6749 & 1 \\
\hline PZT-5H & 0.75 & 21.00 & 33.63 & 650 & 3 & 0.4153 & 4 \\
\hline PZT-5J & 0.74 & 18.80 & 18.59 & 500 & 4 & 0.4302 & 3 \\
\hline PZT-5A & 0.72 & 18.60 & 15.93 & 390 & 5 & 0.3868 & 5 \\
\hline PZT-4 & 0.71 & 17.00 & 14.60 & 372 & 6 & 0.3786 & 6 \\
\hline PZT-8 & 0.64 & 13.50 & 9.80 & 275 & 7 & 0.3309 & 9 \\
\hline $\mathrm{ZnO}$ film & 0.69 & 14.70 & 12.39 & 246 & 8 & 0.3439 & 8 \\
\hline (PVDF-TrFE)75/25 & 0.23 & 300.00 & 0.07 & 33.5 & 9 & 0.0306 & 10 \\
\hline PZT film $(4 \mu \mathrm{m}$ on $\mathrm{Si})$ & 0.23 & 300.00 & 0.07 & 33.5 & 10 & 0.030670 & 11 \\
\hline PVDF & 0.18 & 472 & 0.0673 & 32.5 & 11 & 0.009976 & 12 \\
\hline AIN film & 0.33 & 4.74 & 0.072 & 12 & 12 & 0.358883 & 7 \\
\hline
\end{tabular}

Therefore, the best materials for the piezoelectric plate actuator, according to the results of the FOM and TOPSIS methods, are PIN24\%-PMN-PT and PMN-28\% PT, respectively.

After selecting the optimal materials, various finite element analyses were performed with ANSYS Mechanical Multiphysics. Among the possible analysis types for models containing piezoelectric elements using ANSYS Multiphysics, static, modal, and harmonic analyses were performed in this work. Static response analyses were performed on two individual piezoelectric plates and two different pairs of plates to determine the total deformation or free displacement due to externally applied DC voltage. The two piezoelectric plates were modeled as PMN-28\% PT and PIN24\%-PMN-PT plates, because PMN-28\% PT and PIN24\%-PMN-PT were the top two ranked materials. The two different modes of pairing the plates are: the two plates having the same size, but being made of PMN-28\% PT and PIN24\%-PMN-PT materials, and the two plates being made of the same material, but with different dimensions. Based on the total displacement results, the static response analyses helped to select the better-performing pairing of the two piezoelectric plates to be used as an actuator for the piezoelectric damper project.

The dimension of the larger plate was $30 \mathrm{~mm} \times 30 \mathrm{~mm} \times 10 \mathrm{~mm}$, while the smaller plate dimension was $18 \mathrm{~mm} \times 18 \mathrm{~mm} \times 8 \mathrm{~mm}$.

For comparison, additional static response analysis was performed on a pair of piezoelectric plates of the same material and dimensions. In this case, the material was determined by the results of the individual plates, i.e., the material that results in higher deformation was used in this pair of plates.

In order to carry out the abovementioned types of analyses on models, the characterization of selected materials in terms of compatibility with ANSYS is essential and was done as shown below. 
Property matrices of PMN-28\% PT in Z-polarization:

$$
\begin{aligned}
& C^{E}(6 \times 6)=\left[\begin{array}{cccccc}
11.58 & 10.23 & 9.31 & 0 & 0 & 0 \\
& 11.58 & 9.31 & 0 & 0 & 0 \\
& & 10.71 & 0 & 0 & 0 \\
& & & 6.4 & 0 & 0 \\
\text { sym. } & & & & 6.4 & 0 \\
& & & & & 6.01
\end{array}\right] \times 10^{10} \mathrm{Nm}^{-2}, \\
& e(3 \times 6)=\left[\begin{array}{cccccc}
0 & 0 & 0 & 0 & 0 & 8.69 \\
0 & 0 & 0 & 0 & 8.69 & 0 \\
-13.12 & -13.12 & 21.72 & 0 & 0 & 0
\end{array}\right] \mathrm{Cm}^{-2} \text {, } \\
& \varepsilon^{S}(3 \times 3)=\left[\begin{array}{ccc}
1467 & 0 & 0 \\
0 & 1467 & 0 \\
0 & 0 & 895
\end{array}\right] \times \varepsilon_{0},
\end{aligned}
$$

where: $C^{E}$ denotes the stiffness matrix at constant electric field, $e$ is the piezoelectric stress matrix, $\varepsilon^{S}$ is the dielectric at constant strain matrix, and $\varepsilon_{0}$ is vacuum permittivity; its value is $8.85 p \frac{F}{m}$.

Density of PMN-28\% PT $\rho=8100 \frac{\mathrm{kg}}{\mathrm{m}^{2}}$ [42].

Property matrices of PIN24\%-PMN-PT in Z-polarization:

$$
\begin{aligned}
& C^{E}(6 \times 6)=\left[\begin{array}{cccccc}
12.43 & 10.09 & 11.02 & 0 & 0 & 0 \\
& 12.43 & 11.02 & 0 & 0 & 0 \\
& & 12.45 & 0 & 0 & 0 \\
& & & 6.98 & 0 & 0 \\
\text { sym. } & & & & 6.98 & 0 \\
& & & & & 6.21
\end{array}\right] \times 10^{10} \mathrm{Nm}^{-2}, \\
& e(3 \times 6)=\left[\begin{array}{cccccc}
0 & 0 & 0 & 0 & 0 & 8.52 \\
0 & 0 & 0 & 0 & 8.52 & 0 \\
-9.11 & -9.11 & 17.60 & 0 & 0 & 0
\end{array}\right] \mathrm{Cm}^{-2} \text {, } \\
& \varepsilon^{S}(3 \times 3)=\left[\begin{array}{ccc}
1611 & 0 & 0 \\
0 & 1611 & 0 \\
0 & 0 & 868
\end{array}\right] \times \varepsilon_{0},
\end{aligned}
$$

Density of PIN24\%-PMN-PT $\rho=8122 \frac{\mathrm{kg}}{\mathrm{m}^{2}}$ [42].

All the static response results are presented below in Figures 4-11.
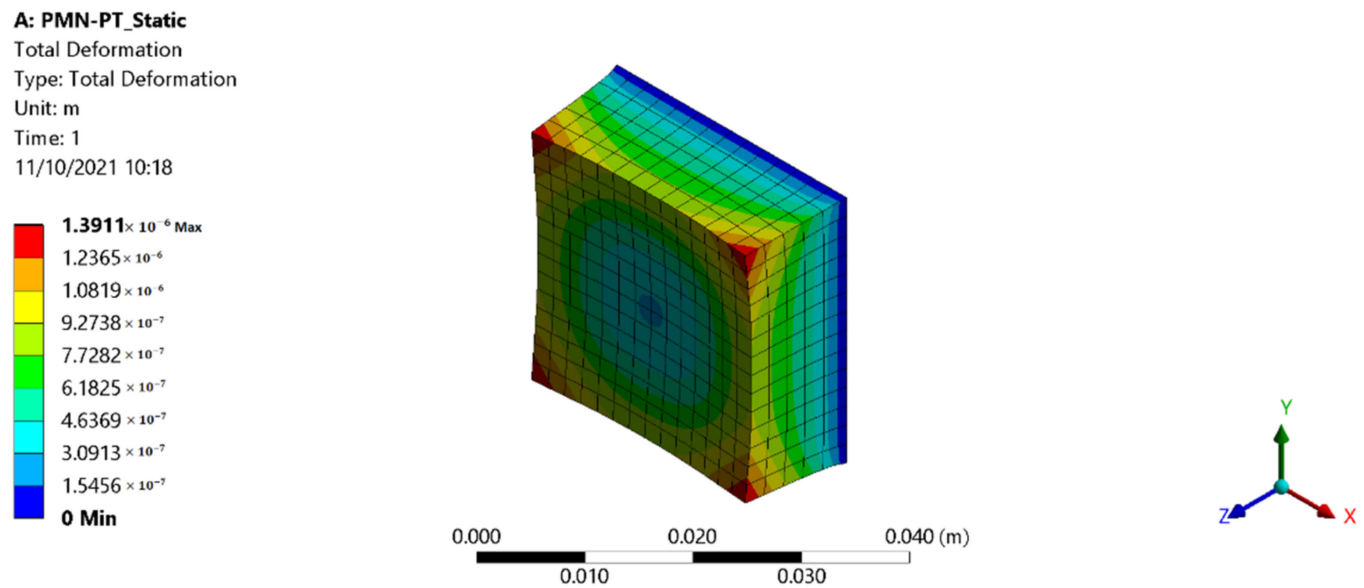

Figure 4. PMN-28\% PT plate static analysis result using Method 1. 


\section{A: PMN-PT_Static}

Total Deformation

Type: Total Deformation

Unit: $m$

Time: 1

$11 / 10 / 202110: 23$
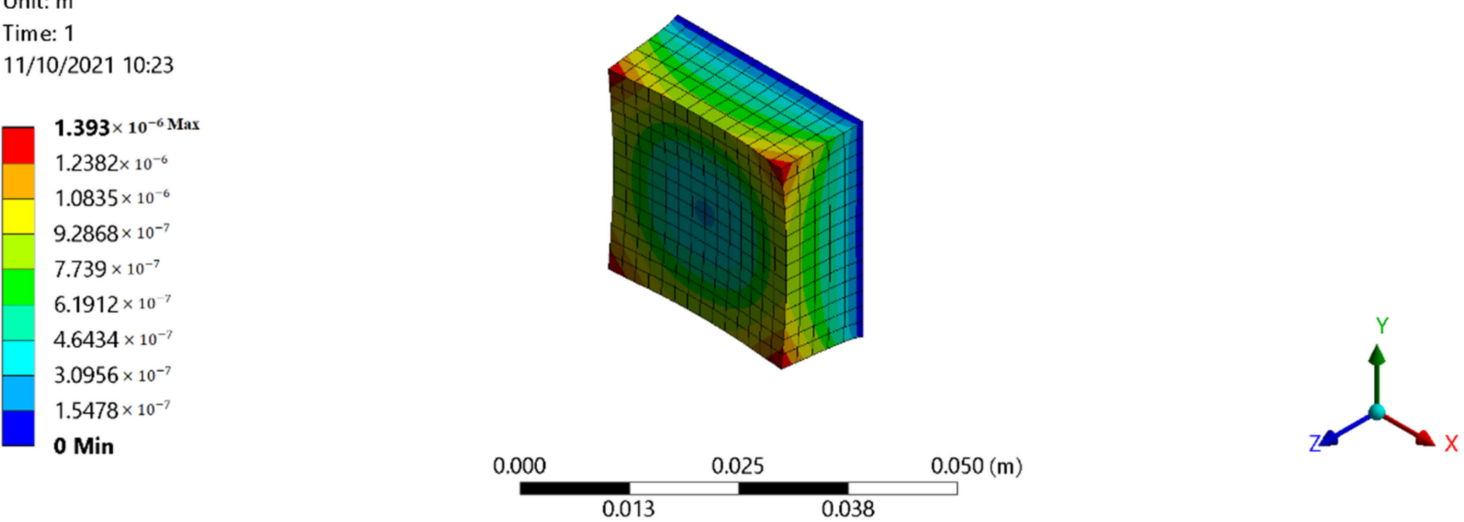

Figure 5. PMN-28\% PT plate static analysis result using Method 2.
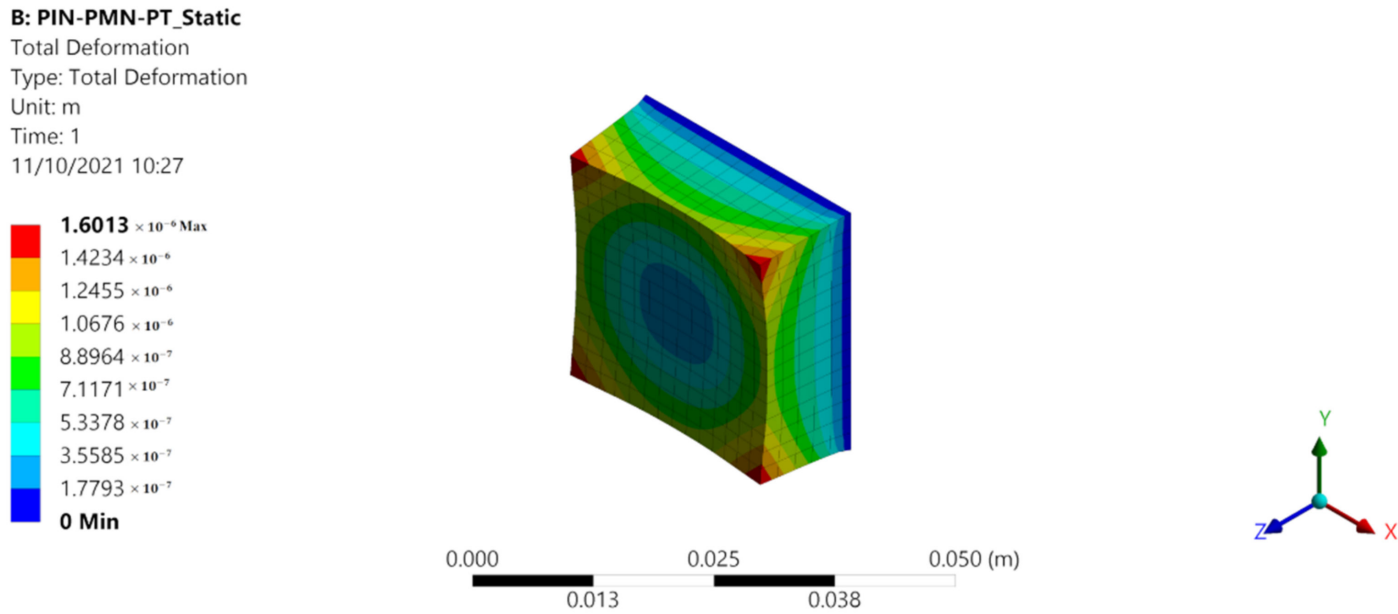

Figure 6. PIN24\%-PMN-PT plate static analysis result using Method 1.

B: PIN-PMN-PT Static

Total Deformation

Type: Total Deformation

Unit: $m$

Time: 1

$11 / 10 / 202110: 27$
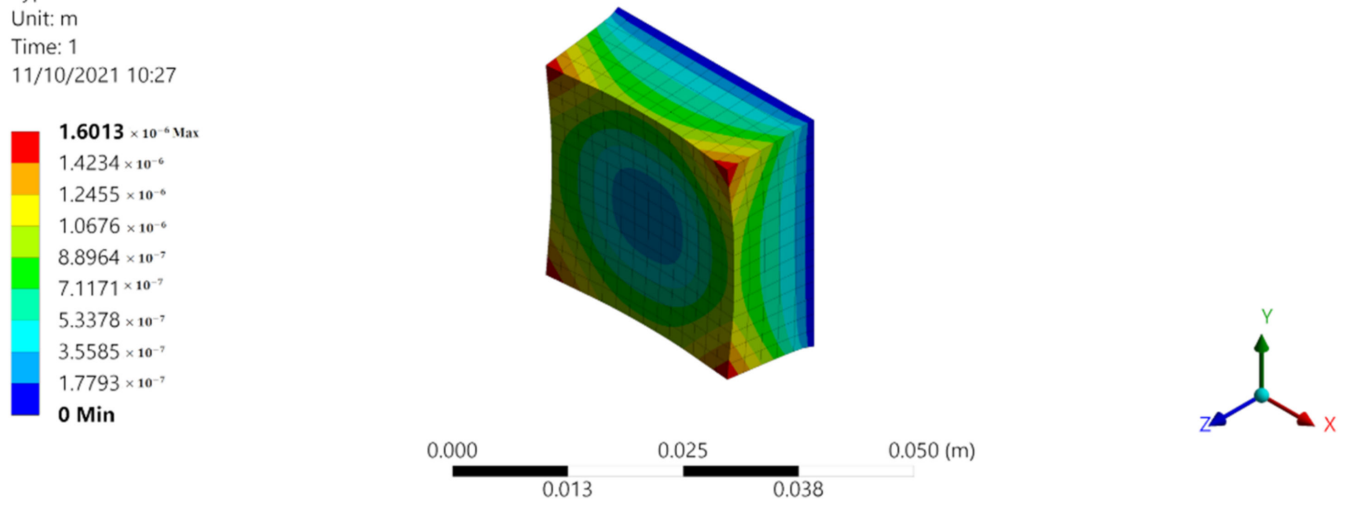

Figure 7. PIN24\%-PMN-PT plate static analysis result using Method 2. 

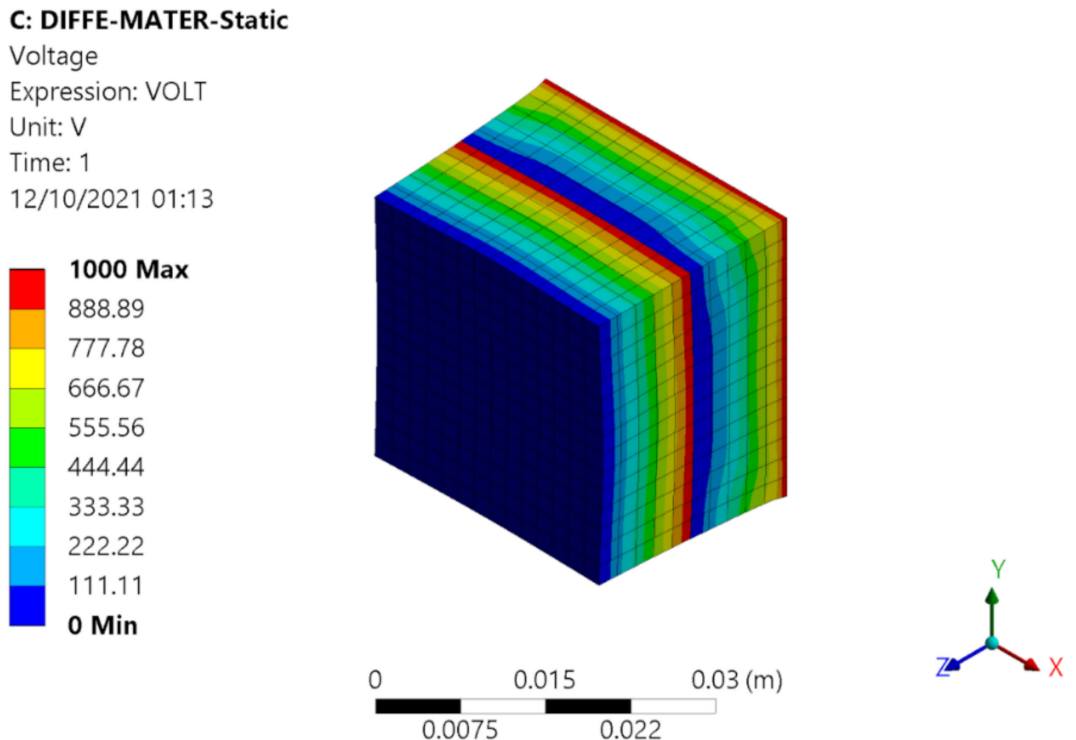

Figure 8. Voltage distribution across plates.
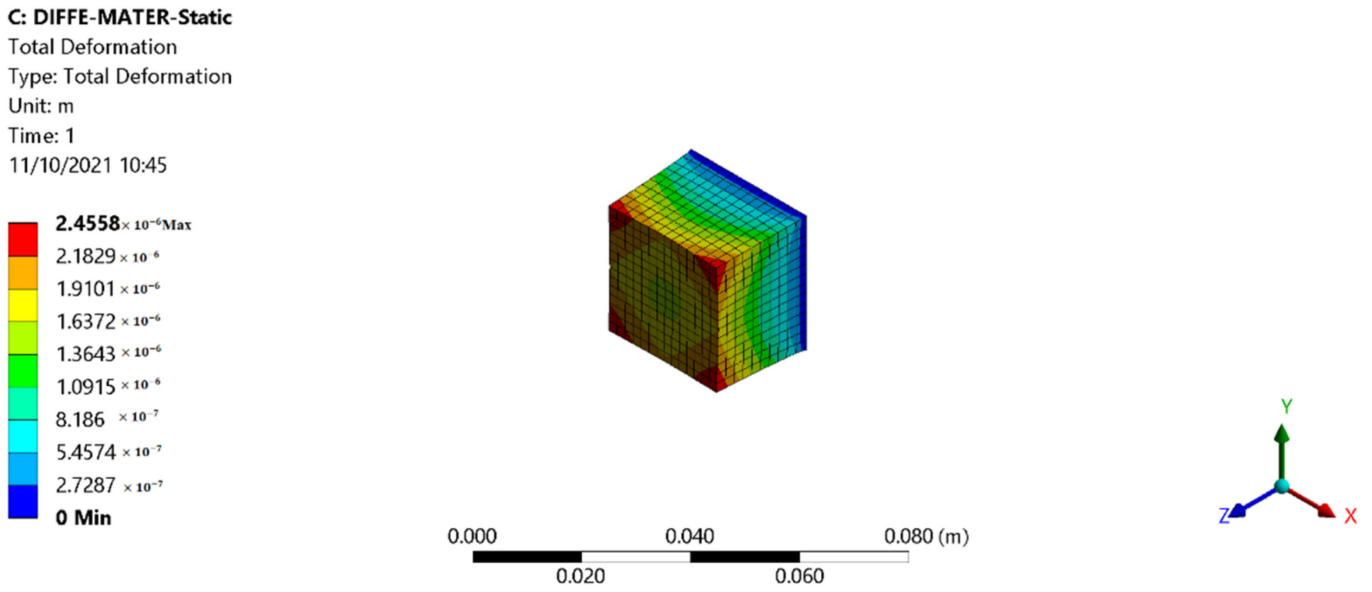

Figure 9. The result of the static analysis of a pair of PMN-24\% PT and PIN24\%-PMN-PT plates using Method 1.
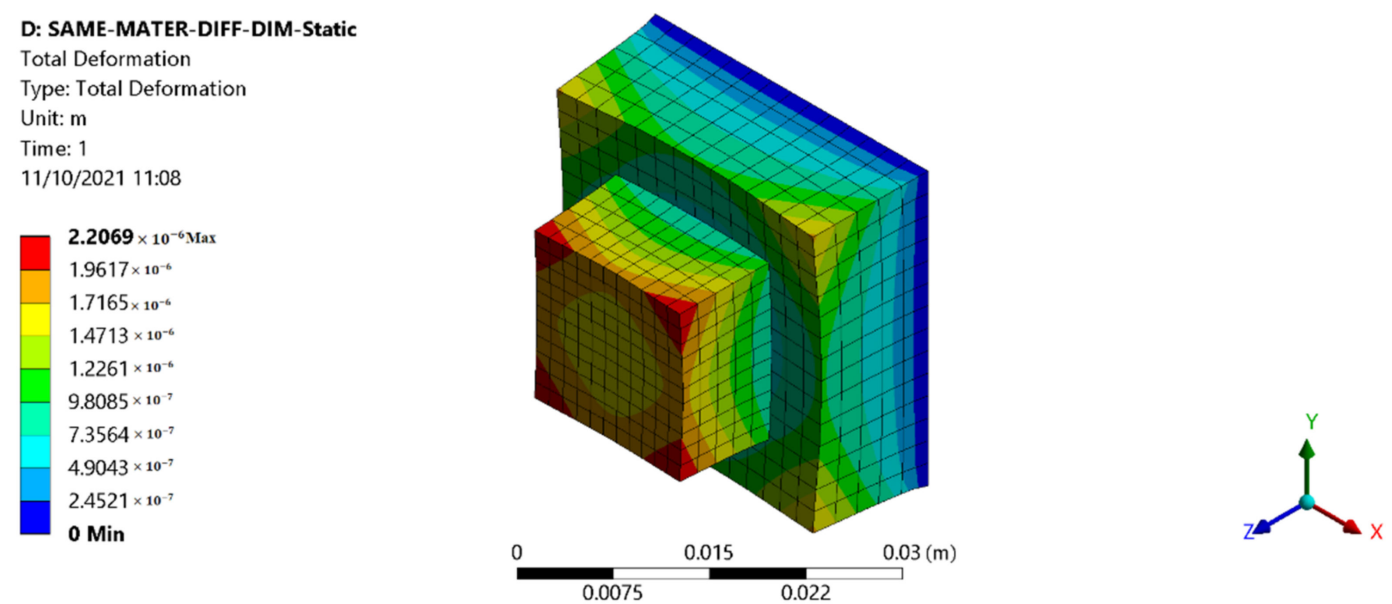

Figure 10. The result of the static analysis of a pair of two PIN24\%-PMN-PT plates of different dimensions using Method 1. 

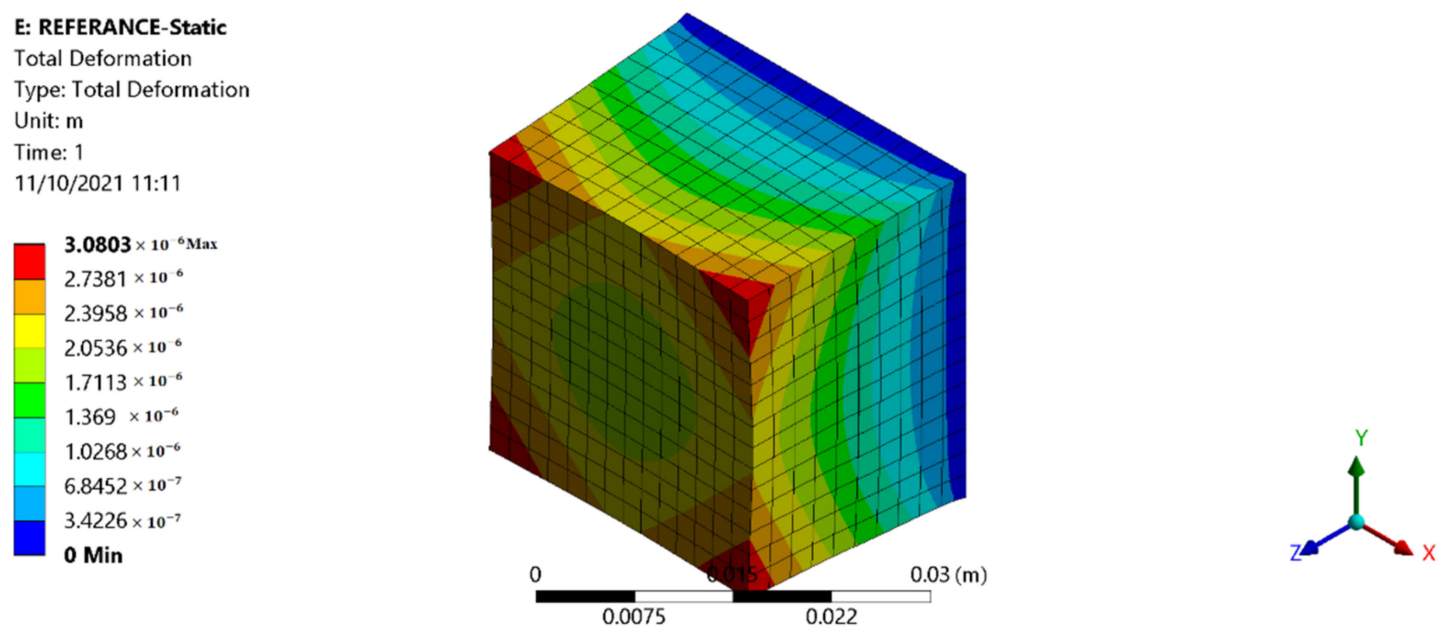

Figure 11. The result of the static analysis of a pair of two PIN24\%-PMN-PT plates using Method 1 for reference purpose.

\section{Contact Between Plates.}

As described in Table 4, the contact between the plates was modeled as bonded contact with a non-electrical coupling between them. Thus, electrical insulation existed between the contact surfaces of the paired plates, as demonstrated by the voltage distribution across the plates.

Method 1 was used to model a pair of plates because this method is more accurate than Method 2 in defining the mesh method and the mesh element of the model.

Based on the results of the static structural analysis of the candidate pairs of plates, it was shown that the pair of PMN-24\% PT and PIN24\%-PMN-PT plates of the same size, i.e., $30 \mathrm{~mm} \times 30 \mathrm{~mm} \times 10 \mathrm{~mm}$, have better actuation performance. Therefore, modal and harmonic response analyses were performed on this optimal pair of plates.

The first ten modal frequencies and the first three modal shapes of the optimal plate pair are shown in Table 5 and Figures 12-14, respectively.

The Z-axis deformation of the front face of the pair on the XY plane was selected for frequency response as shown in Figure 15. The details of frequency analysis settings and its responses are described in Tables 6 and 7 and in Figures 16 and 17.
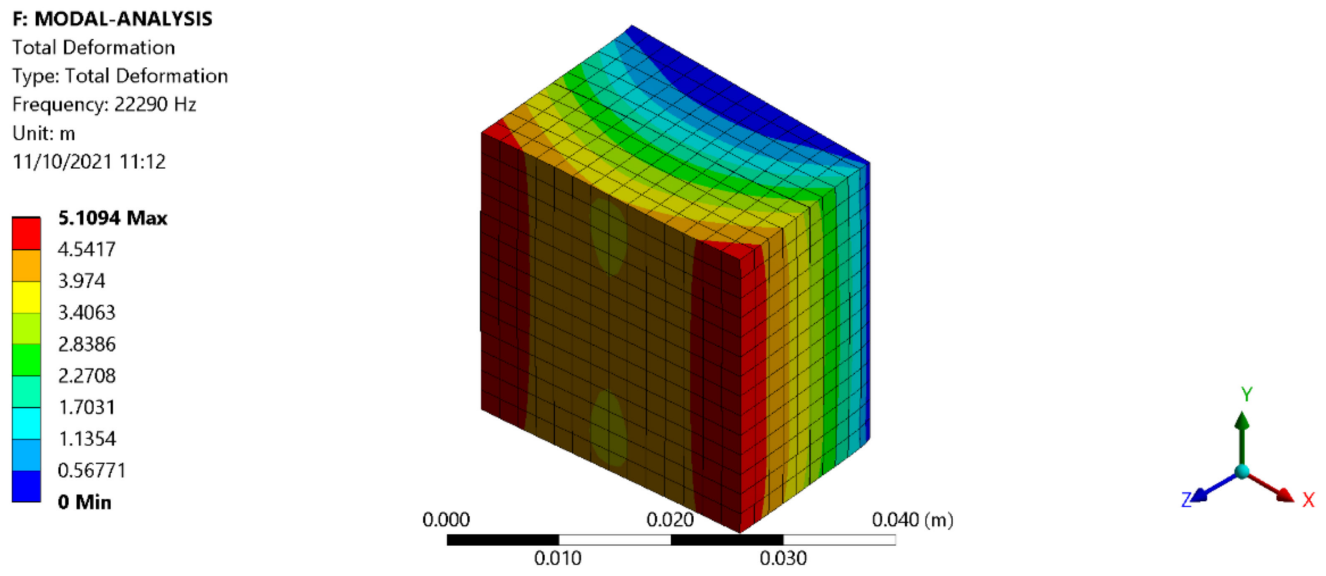

Figure 12. First modal shape of the pair. 
Table 4. Details of contact between plates.

\begin{tabular}{|c|c|}
\hline \multicolumn{2}{|c|}{ Details of Contact Between Plates } \\
\hline \multicolumn{2}{|l|}{ Scope } \\
\hline Scope Method & Geometry selection \\
\hline Contact & Face of one plate \\
\hline Target & Face of other Plate \\
\hline Contact Bodies & Solid \\
\hline Target Bodies & Solid \\
\hline Protected & No \\
\hline \multicolumn{2}{|l|}{ Definition } \\
\hline Type & Bonded \\
\hline Scope Mode & Automatic \\
\hline Behavior & Program Controlled \\
\hline Trim Contact & Program Controlled \\
\hline Trim Tolerance & $1.1726 \times 10^{-4}$ \\
\hline Suppressed & No \\
\hline \multicolumn{2}{|l|}{ Advanced } \\
\hline Formulation & Pure penalty \\
\hline Small Sliding & Program Controlled \\
\hline Detection Method & Program Controlled \\
\hline Penetration Tolerance & Program Controlled \\
\hline Elastic slip tolerance & Program Controlled \\
\hline Normal Stiffness & Factor \\
\hline Normal Stiffness Factor & 0.1 \\
\hline Updated Stiffness & Each Iteration \\
\hline Pinball Region & Program Controlled \\
\hline \multicolumn{2}{|l|}{ Geometric Modification } \\
\hline Contact Geometry Correction & None \\
\hline Target Geometry Correction & None \\
\hline
\end{tabular}

Table 5. The first 10 modal (natural) frequencies of the pair of two larger PIN24\%-PMN-PT and PMN-24\% PT plates.

\begin{tabular}{cc}
\hline Mode & Frequency $\mathbf{( H z )}$ \\
\hline 1 & 22,290 \\
2 & 22,639 \\
3 & 30,827 \\
4 & 31,519 \\
5 & 40,345 \\
6 & 40,539 \\
7 & 44,751 \\
8 & 46,137 \\
9 & 50,216 \\
10 & 52,787 \\
\hline
\end{tabular}


F: MODAL-ANALYSIS Total Deformation 2 Type: Total Deformation Frequency: $22639 \mathrm{~Hz}$ Unit: $\mathrm{m}$

11/10/2021 11:13

$\mathbf{5 . 1 4 0 7}$ Max
4.5695
3.9983
3.4271
2.8559
2.2847
1.7136
1.1424
0.57119
$\mathbf{0}$ Min

F: MODAL-ANALYSIS Total Deformation 3 Type: Total Deformation Frequency: $30827 \mathrm{~Hz}$ Unit: $\mathrm{m}$

11/10/2021 11:13

$\mathbf{6 . 8 3 7 9}$ Max
6.0782
5.3184
4.5586
3.7989
3.0391
2.2793
1.5195
0.75977
$\mathbf{0}$ Min
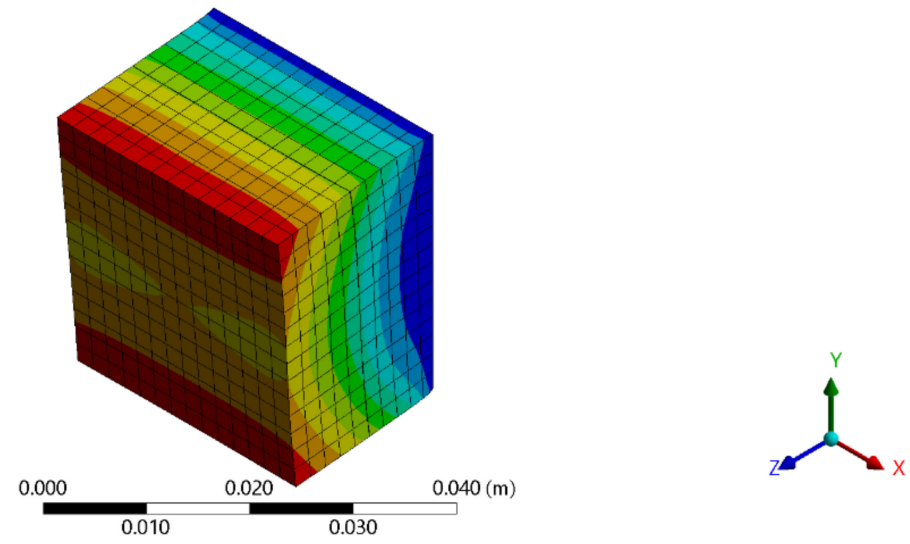

Figure 13. The second modal shape of the pair.
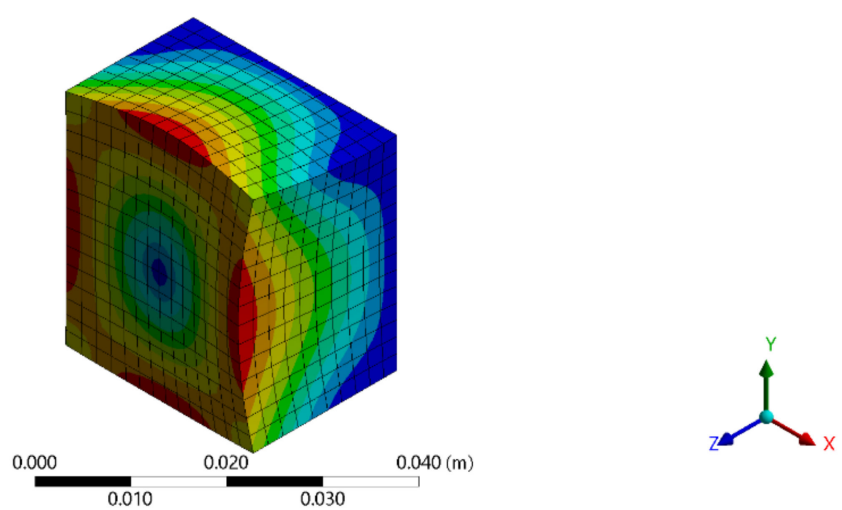

Figure 14. The third modal shape of the pair.

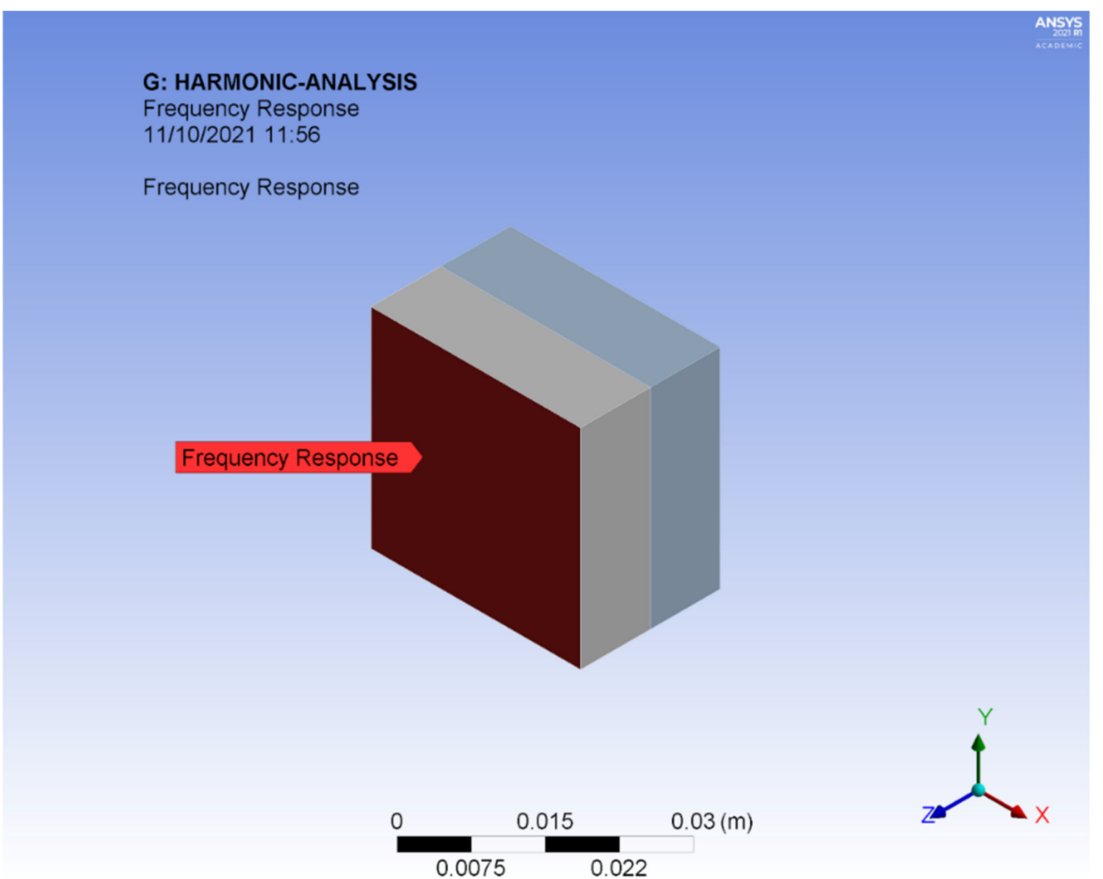

Figure 15. The face selected for frequency response. 
Table 6. Details of frequency analysis settings.

\begin{tabular}{ll}
\hline Details of Frequency Analysis Settings & \\
\hline Frequency Spacing & Frequency Spacing \\
\hline Range Minimum & Range Minimum \\
\hline Range Maximum & Range Maximum \\
\hline Solution Intervals & Solution Intervals \\
\hline User Defined Frequencies & User Defined Frequencies \\
\hline Solution Method & Solution Method \\
\hline Variational Technology & Variational Technology \\
\hline Coriolis Effect & Coriolis Effect \\
\hline Contact Split(DMP) & Contact Split(DMP) \\
\hline Save MAPDL db & Save MAPDL db \\
\hline Contact Summary & Contact Summary \\
\hline Delete Unneeded Files & Delete Unneeded Files \\
\hline Solver Units & Solver Units \\
\hline Solver Unit System & Solver Unit System \\
\hline
\end{tabular}

Table 7. Tabular form of the frequency response.

\begin{tabular}{ccc}
\hline Frequency $\mathbf{( H z )}$ & Amplitude $\mathbf{( m )}$ & Phase Angle (Degree) \\
\hline 3450 & $4.36 \times 10^{-6}$ & $-3.49 \times 10^{-10}$ \\
5900 & $4.55 \times 10^{-6}$ & $-6.09 \times 10^{-10}$ \\
8350 & $4.86 \times 10^{-6}$ & $-8.92 \times 10^{-10}$ \\
10,800 & $5.36 \times 10^{-6}$ & $-1.22 \times 10^{-9}$ \\
13,250 & $6.16 \times 10^{-6}$ & $-1.65 \times 10^{-9}$ \\
15,700 & $7.56 \times 10^{-6}$ & $-2.28 \times 10^{-9}$ \\
18,150 & $1.04 \times 10^{-5}$ & $-3.50 \times 10^{-9}$ \\
20,600 & $1.84 \times 10^{-5}$ & $-7.00 \times 10^{-9}$ \\
23,050 & $1.88 \times 10^{-4}$ & $-8.40 \times 10^{-8}$ \\
25,500 & $1.93 \times 10^{-5}$ & -180 \\
27,950 & $8.45 \times 10^{-6}$ & -180 \\
30,400 & $5.07 \times 10^{-6}$ & -180 \\
32,850 & $3.38 \times 10^{-6}$ & -180 \\
35,300 & $2.27 \times 10^{-6}$ & -180 \\
37,750 & $6.16 \times 10^{-7}$ & -180 \\
40,200 & $2.56 \times 10^{-6}$ & -180 \\
42,650 & $1.64 \times 10^{-6}$ & -180 \\
45,100 & $1.26 \times 10^{-6}$ & -180 \\
47,550 & $9.95 \times 10^{-7}$ & -180 \\
50,000 & $7.96 \times 10^{-7}$ & -180 \\
\hline
\end{tabular}




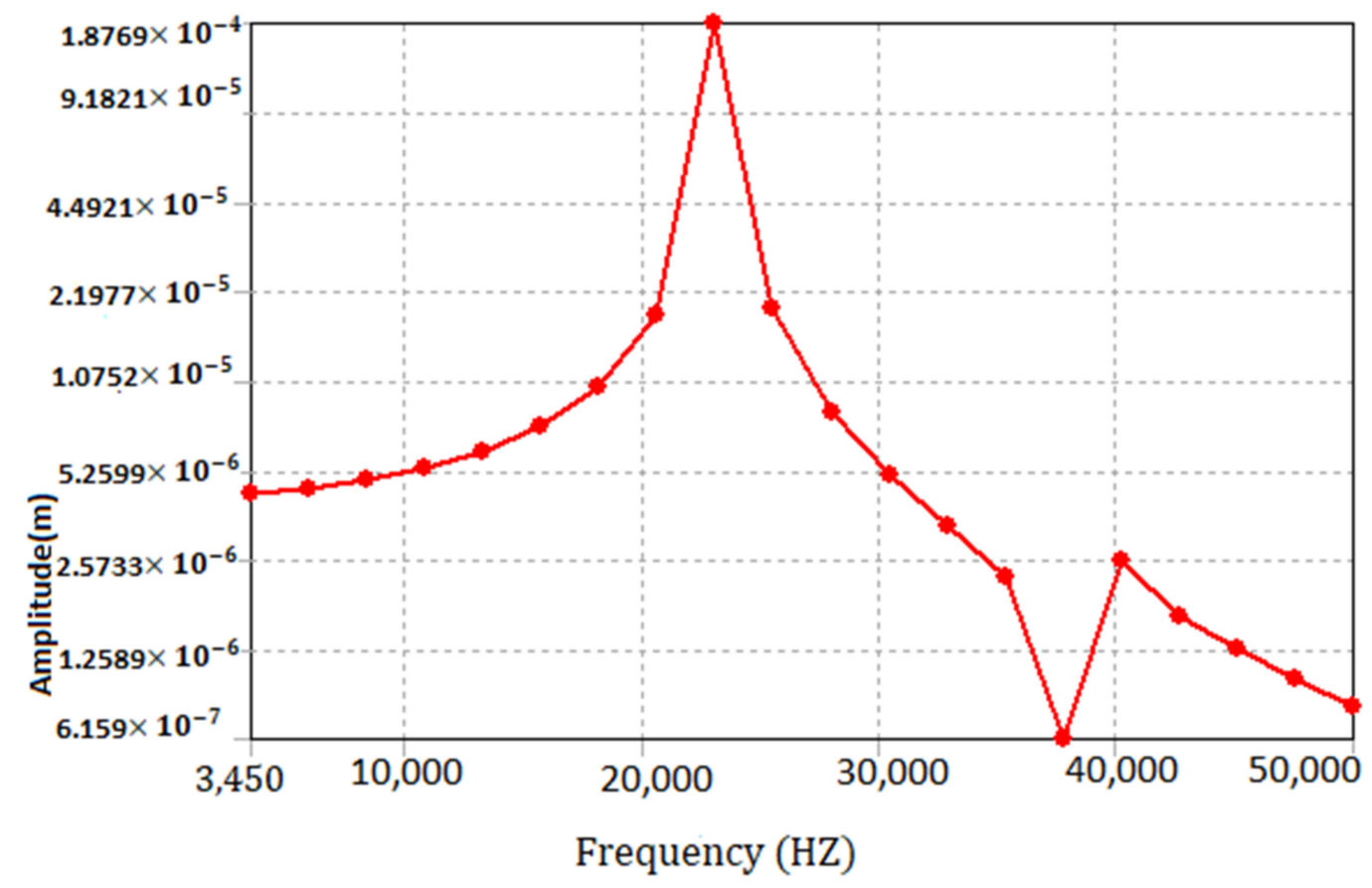

Figure 16. Frequency vs. amplitude graph of the face.

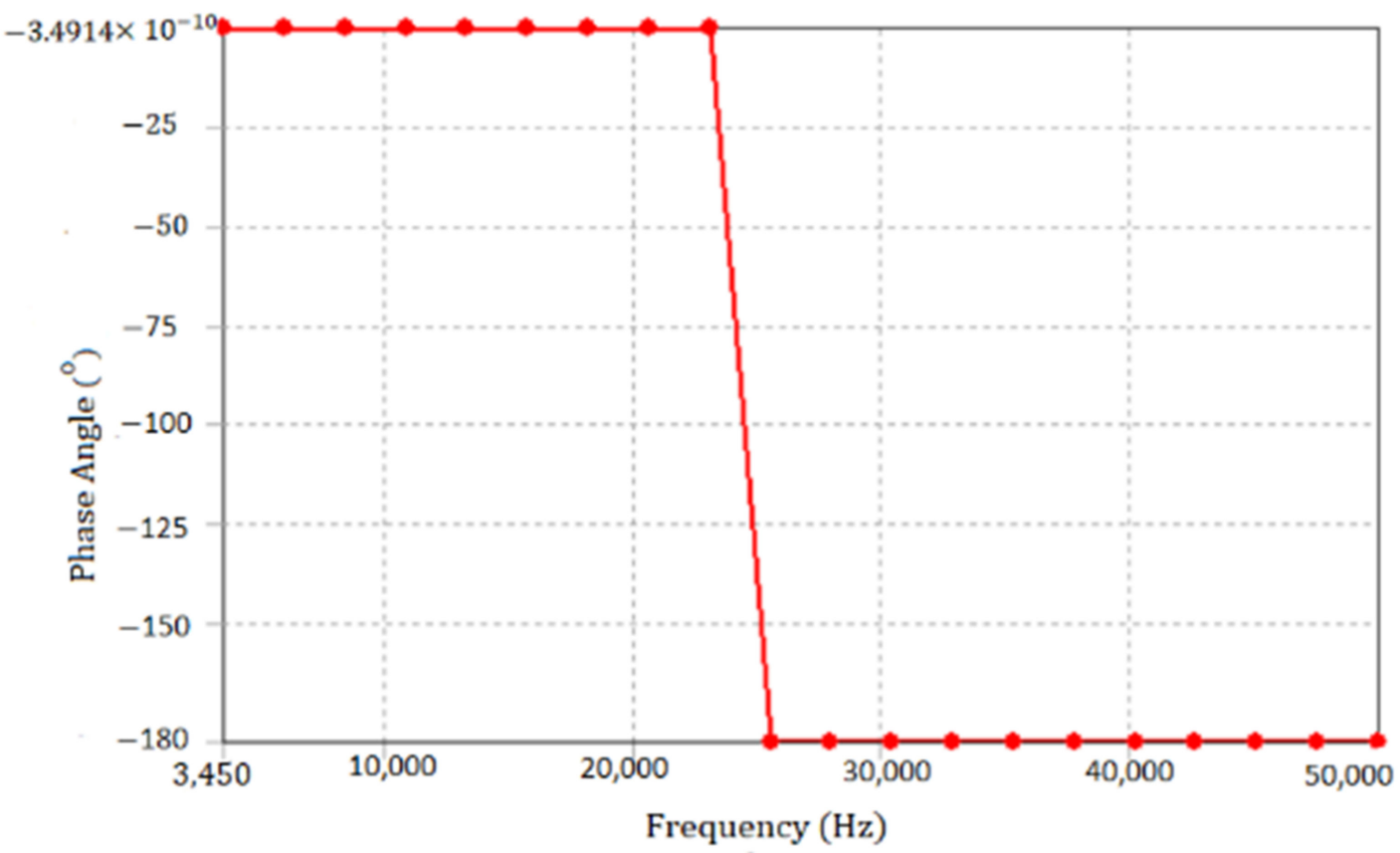

Figure 17. Frequency vs. phase angle graph of the face.

\section{Discussion}

It has been observed that the results of the FOM and TOPSIS analyses are almost consistent in terms of the ranking of the state-of-the-art categories of piezoelectric materials for actuators. The categories in order of decreasing actuator performance in both approaches are single-crystal composites, PZT soft ceramics, PZT hard ceramics, thin films, and polymers. Specifically, PMN-24\% PT is the best piezoelectric material for actuators among the candidates according to TOPSIS analysis, while PIN24\%-PMN-PT is the best according to the FOM approach. The differences in the results of the two material selection approaches 
are due to the fact that the FOM approach considered $d_{33}$ to be the sole determining criteria, while the TOPSIS approach considered the relative weights of $d_{33}, k_{33}, S^{E}{ }_{33}$, and $T_{33}$ as determining factors. Both PMN-24\% PT and PIN24\%-PMN-PT are classes of single crystal composites and ranked at the top in both material selection approaches. In general, the presence of a morphotropic phase boundary in the crystals of both materials with the given composition of each material makes them exhibit excellent piezoelectric properties.

After selecting the optimal materials for the actuator, various finite element analyses were performed with ANSYS Mechanical Multiphysics, as shown in Figure 18. The static analysis results are summarized in Table 8.
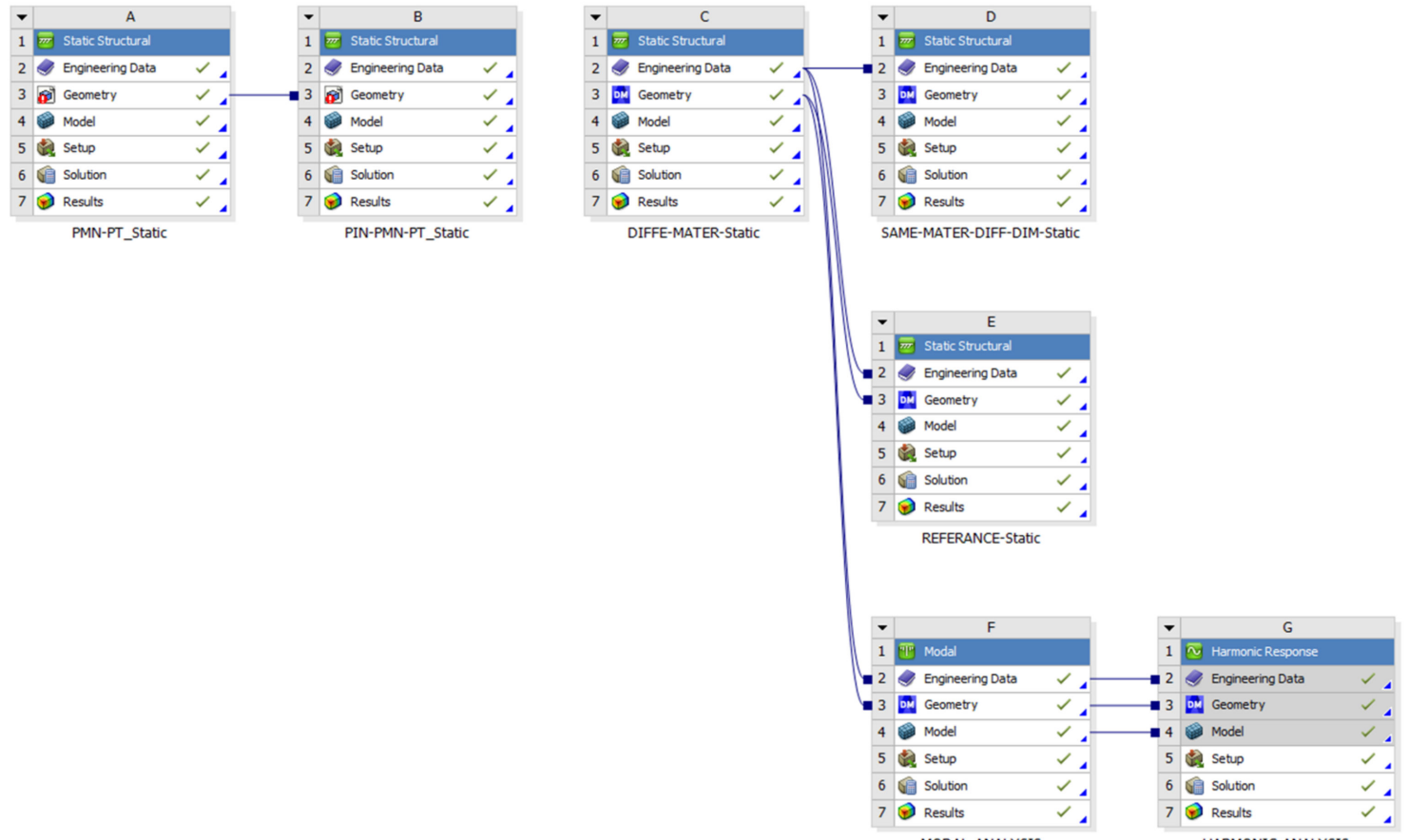

Figure 18. The "project schematic" of all the analyses carried out.

Table 8. Static response analysis results of all cases.

\begin{tabular}{cccc}
\hline No. & Cases & Method & Deformation $(\mu$ m) \\
\hline 1 & PMN-24\% PT plate & Method 1 & 1.39 \\
& & Method 2 & 1.39 \\
2 & PIN24\%-PMN-PT plate & Method 1 & 1.60 \\
3 & Pair of larger PMN-24\% PT and PIN24\%-PMN-PT plates & Method 2 & 1.60 \\
& (Candidate 1) & Method 1 & 2.46 \\
4 & Pair of larger PIN24\%-PMN-PT and smaller PMN-24\% PT plates & Method 1 & 2.21 \\
5 & Pair of two larger PIN24\%-PMN-PT plates (as reference) & Method 1 & 3.08 \\
\hline
\end{tabular}

Of the two-candidate pair of plates, the pair of larger PMN-24\% PT and PIN24\%PMN-PT plates (Case 3) had greater deformation as shown in Table 8 and was found to be the optimal plate actuator for active noise cancellation (AVC). Therefore, modal and harmonic response analyses were performed on this pair of plates. Even though the pair of two larger PIN24\%-PMN-PT plates (Case 5) had the greatest deformation compared to all cases, it was just considered as a reference for the maximum achievable free displacement, due to the high cost of the material. 
The first ten natural frequencies, the first three modal shapes, and the frequency response of the optimal actuator (Case 3) were discussed in the modal and harmonic response analyses sections. From these results, it was observed that the highest longitudinal (3-3) deformation amplitude of the third case is $187.96 \mu \mathrm{m}$ at $23 \mathrm{KHz}$ frequency, which is very close to the second natural frequency.

\section{Conclusions}

This article addressed the daunting task of material selection for piezoelectric plate actuators after a deep review of state-of-the-art piezoelectric materials. This article also went through the multiphysics modeling and simulation of piezoelectric models in two methods in detail to recommend optimal piezoelectric plate actuators for active noise cancellation. According to the results of multiphysics modeling of the two individual piezoelectric plates, it was observed that the two methods of modeling generated consistent results. However, to simplify the rest of the tasks and to consider the exact method, only the first method using APDL command snippets was used, which generated approximately the same results as the theoretical findings in the literature review section. Therefore, based on the results of two candidate plate pairs, the pair of plates of the same dimensions/different materials was recommended as the optimal plate actuator for AVC.

Author Contributions: D.M.: performed all the research tasks including literature review, material selection analysis, multiphysics modeling, and analysis of the results; M.P.: validation, supervision, resources, funding acquisition, supervised the research and reviewed the paper; A.W.: validation, supervision, resources, supervised the research. All authors have read and agreed to the published version of the manuscript.

Funding: This research received no external funding.

Institutional Review Board Statement: Not applicable.

Informed Consent Statement: Not applicable.

Data Availability Statement: Not applicable.

Conflicts of Interest: The authors declare no conflict of interest.

\section{References}

1. Berardengo, M.; Cigada, A.; Manzoni, S.; Vanali, M. Vibration Control by Means of Piezoelectric Actuators Shunted with LR Impedances: Performance and Robustness Analysis. Shock Vib. 2015, 2015, 704265. [CrossRef]

2. Botta, F.; Toccaceli, F. Piezoelectric Plates Distribution for Active Control of Torsional Vibrations. Actuators 2018, 23, 23. [CrossRef]

3. Von Flotow, A.; Hagood, N.W. Damping of structural vibrations with piezoelectric materials and passive electrical networks. J. Sound Vib. 1991, 146, 26.

4. Kuo, M.; Morgan, D.R. Active Noise Control: A Tutorial Review. Proc. IEEE 1999, 87, 943-973. [CrossRef]

5. Song, L.; Xia, P. Active Vibration Control by Harmonic Input Compensation for Piezoelectric Stack Actuator Nonlinearity. J. Aircr. 2014, 51, 1-6. [CrossRef]

6. Zhang, S.; Yu, F.; Li, F.; Jiang, X.; Lee, H.-Y.; Luo, J.; Shrout, T.R. Recent Developments in Piezoelectric Crystals. J. Korean Ceram. Soc. 2018, 55, 1-21. [CrossRef]

7. Chauhan, A.; Vaish, R.; Bowen, C. Piezoelectric material selection for ultrasonic transducer and actuator applications. J. Mater. Des. Appl. 2015, 229, 1-12. [CrossRef]

8. Noliac. Actuators for Quasi-Static Applications_Tutorial. Available online: http://www.noliac.com/fileadmin/user_upload/ documents/Tutorials/Tutorials_Actuator_1.pdf (accessed on 12 March 2021).

9. Moita, J.M.S.; Correia, I.F.P.; Soares, C.M.M.; Soares, C.A.M. Active control of adaptive laminated structures with bonded piezoelectric sensors and actuators with bonded piezoelectric sensors and actuators. Comput. Struct. 2004, 82, 1349-1358.

10. Caruso, G.; Galeani, S.; Menini, L. Active vibration control of an elastic plate using multiple piezoelectric sensors and actuators. Simul. Model. Pract. Theory 2003, 11, 403-419. [CrossRef]

11. Reddy, J.N. On laminated composite plates with integrated sensors and actuators. Eng. Struct. 1999, 21, 568-593. [CrossRef]

12. Luo, Y.; Xie, S.; Zhang, X. The actuated performance of multi-layer piezoelectric actuator in active vibration control of honeycomb sandwich panel. J. Sound Vib. 2008, 317, 3-5. [CrossRef]

13. Joshi, A. Multi-layered piezoelectric inserts as vibration control actuators. J. Sound Vib. 2002, 253, 917-925. [CrossRef]

14. Chauhan, A. Material Selection for Piezoelectric Devices. Adv. Sci. Eng. Med. 2013, 5, 715-719. [CrossRef] 
15. Zhou, Q.; Lam, K.H.; Zheng, H.; Qiu, W.; Shung, K.K. Piezoelectric single crystal ultrasonic transducers for biomedical applications. Prog. Mater. Sci. 2014, 66, 87-111. [CrossRef]

16. Park, S.-E.; Shrout, T.R. Ultrahigh strain and piezoelectric behavior in relaxor based ferroelectric single crystals. J. Appl. Phys. 1998, 82, 1804. [CrossRef]

17. Yin, Z.-W.; Luo, H.-S.; Wang, P.-C.; Xu, G.-S. Growth, characterization and properties of relaxor ferroelectric PMN-PT single crystals. Ferroelectrics 2011, 231, 97-102. [CrossRef]

18. Tian, J.; Han, P.; Huang, X.; Pan, H. Improved stability for piezoelectric crystals grown in the lead indium niobate-lead magnesium niobate-lead titanate system. Appl. Phys. Lett. 2007, 91, 222903. [CrossRef]

19. Piezo.com. Materials Technical Data (Typical Values)—Piezo.com. Available online: https://info.piezo.com/hubfs/Data-Sheets/ piezo-material-properties-data-sheet-20201112.pdf (accessed on 12 April 2021).

20. Aksel, E.; Jones, L.J. Advances in Lead-Free Piezoelectric Materials for Sensors and Actuators. Sensors 2010, 10, 1935-1954. Available online: https:/ / www.mdpi.com/journal/sensors (accessed on 15 July 2021). [CrossRef]

21. Ramadan, K.; Sameoto, D.; Evoy, S. A review of piezoelectric polymers as functional materials for electromechanical transducers. Smart Mater. Struct. 2014, 1, 3-22. [CrossRef]

22. Dargaville, T.R.; Celina, M.C.; Elliott, J.M.; Jones, G.D.; Mowery, D.M.; Assink, R.A.; Clough, R.L.; Martin, J.W. Characterization, Performance and Optimization of PVDF as a Piezoelectric Film for Advanced Space Mirror Concepts; Sandia National Laboratories: Albuquerque, NM, USA, 2005.

23. Wang, J.-J.; Hsu, T.-H.; Yeh, C.-N.; Tsai, J.-W.; Su, Y.-C. Piezoelectric polydimethylsiloxane films for MEMS transducers. J. Micromech. Microeng. 2012, 22, 015013. [CrossRef]

24. Gerhard-Multhaupt, R. Less can be More-Holes in Polymers lead to a New Paradigm of Piezoelectric Materials for Electret Transducers. IEEE Trans. Dielectr. Electr. Insul. 2002, 9, 850-859. [CrossRef]

25. Zhang, X.; Hillenbrand, J.; Sessler, G.M. Piezoelectric d33 coefficient of cellular polypropylene subjected to expansion by pressure treatment. Appl. Phys. Lit. 2004, 8, 1226. [CrossRef]

26. Feng, Y.; Hagiwara, K.; Iguchi, Y.; Suzuki, Y. Trench-filled cellular parylene electret for piezoelectric transducer. Appl. Phys. Lett. 2012, 100, 262901. [CrossRef]

27. Matt, H.M.; di Scalea, F.L. Macro-fiber composite piezoelectric rosettes for acoustic source location in complex structures. Smart Mater. Struct. 2007, 16, 1489. [CrossRef]

28. Liu, C.; Djuth, F.; Li, X.; Chen, R.; Zhou, Q.; Shung, K.K. Micromachined high frequency PMN-PT/epoxy 1-3 composite ultrasonicannular array. Ultrasonics 2012, 52, 497-502. [CrossRef]

29. Prashanthi, K.; Naresh, M.; Seena, V.; Thundat, T.; Rao, V.R. A Novel Photo Plastic Piezoelectric Nanocomposite for MEMS Applications. J. Microelectromech. Syst. 2012, 21, 259-261. [CrossRef]

30. Qin, L.; Chen, C.; Cheng, H.; Chen, Q.; Li, J.-F.; Wang, Q.-M. Viscosity sensor using ZnO and AlN thin film bulk acoustic resonators with tilted polar c-axis orientations. J. Appl. Phys. 2011, 110, 094511. [CrossRef]

31. Zhang, X.; Huang, J.; Wang, X.; Xia, Z. Piezoelectricity and dynamic characteristics of laminated fluorocarbon films. IEEE Trans. Dielectr. Electr. Insul. 2010, 17, 1001-1007. [CrossRef]

32. Kirjavainen, K. Electromechanical Film and Procedure for Manufacturing Same. U.S. Patent US4654546A, 31 March 1987.

33. Chakrabortya, S.; Chatterjee, P. Selection of materials using multi-criteria decision-making methods with minimum data. Decis. Sci. Lett. 2013, 2, 135-148. [CrossRef]

34. Staworko, M.; Uhl, T. Modelling and Simulation of Piezoelectric Elements-Comparison of Available Methods and Tools. J. Mech. 2008, 24, 1-11.

35. Dudhat, P.; Li, Q.; Ren, S. ANSYS Simulation of Piezoelectric Patch for Energy Harvesting. In Proceedings of the 2019 ASEE Zone I Conference \& Workshop, Niagara Falls, NY, USA, 11-15 April 2019; pp. 1-10.

36. Benjeddou, A. Advances in piezoelectric finite element modeling of adaptive structural elements: A survey. Comput. Struct. 2000, 76, 17. [CrossRef]

37. Nguyen, V.-T.; Kumar, P.; Chuang Leong, J.Y. Finite Element Modeling and Simulations of Piezoelectric Actuators Responses with Uncertainty Quantification. Computation 2018, 6, 60.

38. DeAngelis, A.; Schulze, W. Performance of PZT8 versus PZT4 piezoceramic materials in ultrasonic transducers. Phys. Procedia 2016, 87, 85-92. [CrossRef]

39. CTS Corporation. Piezoelectric PMN-PT Single Crystal Products. Available online: https://www.ctscorp.com/wp-content/ uploads / 2016.12.15-Single-Crystal-Brochure.pdf (accessed on 15 June 2021).

40. Rahim, M.R. Multiphysics Modeling and Simulation Process to Develop Thin Piezoelectric Film Sensors to Measure the Vibration of Structures with Complex Shapes and Boundary Conditions; University of North Dakota: Grand Forks, ND, USA, 2012.

41. Zieliński, G. Smart Tech. Available online: http://bluebox.ippt.pan.pl/ \{\}tzielins/index.php?im=1\&id=lectures.html (accessed on 21 June 2021).

42. Baek, S.H.; Rzchowski, M.S.; Aksyuk, V.A. Giant piezoelectricity in PMN-PT thin films: Beyond PZT. MRS Bull. 2012, 37, 1022-1029. [CrossRef] 